\title{
Characterization of the AD7C-NTP cDNA Expression in Alzheimer's Disease and Measurement of a 41-kD Protein in Cerebrospinal Fluid
}

\author{
Suzanne M. de la Monte, ${ }^{\star \ddagger \S}$ Kasra Ghanbari," William H. Frey, ${ }^{\star *}$ Iraj Beheshti, \\ Hossein A. Ghanbari," and Jack R. Wands" \\ $*$ MGH Cancer Center, ${ }^{\ddagger} M G H$ Alzheimer’s Disease Research Center, ${ }^{\S}$ Department of Pathology and $\|^{\|}$epartment of Medicine, \\ Massachusetts General Hospital and Harvard Medical School, Boston, Massachusetts 02114; "Nymox Corporation, Rockville, Maryland \\ 20895; **Ramsey Alzheimer’s Treatment and Research Center, St. Paul, Minnesota 55101; and ${ }^{\ddagger}$ University of California Medical Center, \\ San Francisco, California 94143
}

\begin{abstract}
We have isolated a novel Alu sequence-containing cDNA, designated AD7c-NTP, that is expressed in neurons, and overexpressed in brains with Alzheimer's disease (AD). The 1,442-nucleotide AD7c-NTP cDNA encodes an $\sim 41-\mathrm{kD}$ protein. Expression of AD7c-NTP was confirmed by nucleic acid sequencing of reverse transcriptase PCR products isolated from brain. AD7c-NTP cDNA probes hybridized with 1.4 kB mRNA transcripts by Northern blot analysis, and monoclonal antibodies generated with the recombinant protein were immunoreactive with $\sim 41-45-\mathrm{kD}$ and $\sim 18-21$ $\mathrm{kD}$ molecules by Western blot analysis. In situ hybridization and immunostaining studies localized AD7c-NTP gene expression in neurons. Using a quantitative enzyme-linked sandwich immunoassay (Ghanbari, K., I. Beheshti, and H. Ghanbari, manuscript submitted for publication) constructed with antibodies to the recombinant protein, AD7cNTP levels were measured under code in 323 clinical and postmortem cerebrospinal fluid (CSF) samples from $A D$, age-matched control, Parkinson's disease, and neurological disease control patients. The molecular mass of the AD7cNTP detected in CSF was $\sim 41 \mathrm{kD}$. In postmortem CSF, the mean concentration of AD7c-NTP in cases of definite $\mathrm{AD}(9.2 \pm 8.2 \mathrm{ng} / \mathrm{ml})$ was higher than in the aged control group (1.6 $\pm 0.9 ; P<0.0001)$. In CSF samples from individuals with early possible or probable $\mathrm{AD}$, the mean concentration of AD7c-NTP (4.6 \pm 3.4$)$ was also elevated relative to the levels in CSF from age-matched (1.2 \pm 0.7$)$ and neurological disease (1.0 \pm 0.9$)$ controls, and ambulatory patients with Parkinson's disease $(1.8 \pm 1.1)$ (all $P<0.001)$. CSF levels of AD7c-NTP were correlated with Blessed dementia scale scores $(r=0.66 ; P=0.0001)$ rather than age $(r=$ $-0.06 ; P>0.1)$. In vitro studies demonstrated that overexpression of AD7c-NTP in transfected neuronal cells promotes neuritic sprouting and cell death, the two principal
\end{abstract}

Address correspondence to Suzanne M. de la Monte, M.D., MGH East Cancer Center, 149 13th Street, Room 7308, Massachusetts General Hospital, Charlestown, MA 02129. Phone: 617-726-5602; FAX: 617-726-5609; E-mail: delamont@helix.MGH.harvard.edu

Received for publication 20 March 1997 and accepted in revised form 7 October 1997.

J. Clin. Invest.

(C) The American Society for Clinical Investigation, Inc. 0021-9738/97/12/3093/12 \$2.00

Volume 100, Number 12, December 1997, 3093-3104

http://www.jci.org neuroanatomical lesions correlated with dementia in AD. The results suggest that abnormal AD7c-NTP expression is associated with $\mathrm{AD}$ neurodegeneration, and during the early stages of disease, CSF levels correlate with the severity of dementia. (J. Clin. Invest. 1997. 100:3093-3104.) Key words: AD7c-NTP • Alzheimer's Disease • cerebrospinal fluid • enzyme immunoassay $\bullet$ neurodegeneration $•$ Alu sequence

\section{Introduction}

Alzheimer's disease $(\mathrm{AD})^{1}$ is the most prevalent neurodegenerative disease and the most common cause of dementia in the Western hemisphere. AD neurodegeneration is characterized by prominent atrophy of corticolimbic structures with neuronal loss, neurofibrillary tangle formation, aberrant proliferation of neurites, senile plaques, and $\beta$ A4-amyloid deposition in the brain (1). Approximately $90 \%$ of AD occurs sporadically. The cause is unknown, but the most important overall risk factor is aging (2). The apolipoprotein $\epsilon 4$ genotype (3) and a family history of Trisomy 21 Down syndrome (4) increase risk or accelerate the course of sporadic AD. Familial forms of AD, which account for $5-10 \%$ of the cases, have been linked to mutations in the amyloid precursor protein (APP) gene (5) located on Chromosome 21, or presenilin genes located on Chromosomes 1 and 14 (6-10). Overexpression and abnormal cleavage of APP may promote AD neurodegeneration since all individuals with Trisomy 21 Down syndrome who survive beyond the fourth decade develop AD with extensive central nervous system (CNS) accumulations of $\beta$ A4-amyloid (11), and experimentally, $\beta$ A4-amyloid is neurotoxic and apoptogenic (12). In addition, missense mutations in presenilin 1 , as occur in nature, cause vasculopathy and massive accumulations of amyloid beta-peptides in the brain (13).

CNS biochemical and molecular abnormalities identified in AD include: (a) increased phosphorylation of tau and other cytoskeletal proteins in neurons (14); (b) aberrant expression of genes modulated with neuritic sprouting such as the growth associated protein, GAP-43 (15), constitutive endothelial nitric oxide synthase (16), transforming growth factor (TGF) $\beta$ (17), and metallothionine-3 (18); (c) increased expression of genes associated with glial cell activation, such as glial fibrillary

1. Abbreviations used in this paper: $\mathrm{AD}$, Alzheimer's Disease; $\mathrm{ADRI}$, rabbit polyclonal antibody; BDSS, Blessed dementia scale score; CIL, confidence interval limits; CSF, cerebrospinal fluid; ELSIA; enzymelinked sandwich immunoassay; MS, multiple sclerosis; PD, Parkinson's disease; HPLC, high performance liquid chromatography; RTPCR, reverse transcriptase-polymerase chain reaction. 
acidic protein (19) and alpha-1 antichymotrypsin (20); and (d) altered expression of genes that protect neurons from either cytotoxic or programmed cell death, including sulfated glycoprotein-2 (21), cathepsin D (22), superoxide dismutase 1 (23), mitochondrial cytochrome oxidase (24), C1q component of complement (25), Calbindin D28k (26), and bcl-2 (27). In previous studies, we demonstrated increased immunoreactivity in AD brains using a polyclonal antisera prepared against a pancreatic protein (28). Using such polyclonal antibodies, we isolated the AD7c-NTP cDNA from an AD brain expression library. This study characterizes the AD7c-NTP cDNA and its over-expression in AD brains, and demonstrates increased levels of the corresponding protein in cerebrospinal spinal fluid (CSF) samples from individuals with early, i.e., possible or probable, as well as advanced AD using a recently developed quantitative enzyme-linked sandwich immunoassay (ELSIA).

\section{Methods}

Isolation of the $A D 7 c-N T P c D N A$. A cDNA library was prepared commercially (Invitrogen Corp., San Diego, CA) using RNA extracted from the temporal lobe of an individual with end-stage AD. The library was ligated into the pcDNA2 vector. To isolate the AD7c-NTP gene, $\sim 5 \times 10^{5}$ transformed and IPTG induced Escherichia coli colonies were screened using polyclonal antibodies to human pancreatic thread protein (28), followed by radiolabeled antihuman IgG (Amersham Corp., Arlington Heights, IL) (29). Restriction endonuclease fragments (XhoI-PstI; PstI-PvuII; PvuII-HindIII) of AD7c-NTP were subcloned into pGem7 (Promega Corp., Madison, WI), and the nucleotide sequence of both strands was determined by the dideoxy nucleotide chain termination method using T7 DNA polymerase (29). The DNA sequence was assembled with the MacVector Software version 4.5 and analyzed using a Sequence Analysis Software of the Genetics Computer Group version 7.3 as implemented on a MicroVax II computer. Database searches were performed using the BLAST network service of the National Center for Biotechnology Information.

In vitro expression. Antisense and sense cRNAs were transcribed from AD7c-NTP cDNA plasmid linearized with Kpn1 and Xho1, respectively. The cRNA transcripts were translated in a rabbit reticulocyte lysate system (Stratagene, Inc., La Jolla, CA) in the presence of $\left[{ }^{35}\right.$ S $]$ methionine (Dupont-New England Nuclear, Boston, MA), and the products of in vitro translation were analyzed by denaturing PAGE (SDS-PAGE) and autoradiography. The AD7c-NTP cDNA was ligated into the pTrcHis expression vector (Invitrogen Corp.) which encodes a 5' 6-His Tag sequence used to isolate the fusion protein by metal chelate chromatography. The fusion protein was affinity purified using ProBond resin (Invitrogen Corp.), and detected by Western blot analysis with antibodies to the T7-tag fusion partner (Novagen, Inc., Madison, WI).

Generation of polyclonal and monoclonal antibodies to recombinant $A D 7 c-N T P$. Polyclonal antibodies were generated in rabbits immunized with affinity purified recombinant AD7c-NTP protein. Monoclonal antibodies ( $\mathrm{mAb}$ ) were generated in Balb/c mice immunized with purified recombinant AD7c-NTP protein. These studies employed polyclonal and the N3I4, N2J1, N2T8, and N2U6 monoclonal AD7c-NTP antibodies as described previously (30).

Human brain tissue. Human brain tissue was obtained from the Alzheimer's Disease Research Center brain bank at the Massachusetts General Hospital (MGH-ADRC). All brains were harvested within $12 \mathrm{~h}$ of death and the histopathological diagnosis of $\mathrm{AD}$ was rendered using CERAD criteria (31). The AD group $(n=17)$ had a

2. Ghanbari, K., I. Beheshti, and H. Ghanbari, manuscript submitted for publication. mean age of $76.3 \pm 8.8 \mathrm{yr}$ and the control group $(n=11)$ had a mean age of $78.0 \pm 6.2 \mathrm{yr}$. Fresh frozen frontal and temporal lobe tissue was used for Northern and Western blot analyses. Postmortem (CSF) samples (8 AD; 7 age-matched controls) were used to detect AD7cNTP by Western blot analysis. Paraffin-embedded histological sections were used to localize AD7c-NTP gene expression by in situ hybridization and immunohistochemical staining.

Northern analysis of AD7c-NTP $m R N A$ expression and in situ hybridization. Samples $(15 \mu \mathrm{g})$ of total RNA isolated (29) from AD and aged control frontal lobe tissue (Brodmann Area 11), and normal adult human kidney, liver, spleen, gastrointestinal tract, ovaries, fallopian tubes, uterus, thyroid, lung, skeletal muscle, and pancreas were subjected to Northern hybridization analysis using $2 \times 10^{6} \mathrm{dpm} / \mathrm{ml}$ of $\left[\alpha^{32} \mathrm{P}\right] \mathrm{dCTP}-$ labeled AD7c-NTP cDNA as a probe (29). To evaluate RNA loading, the blots were stripped of probe and rehybridized with a 10 -fold molar excess of a $\left[\gamma^{32} \mathrm{P}\right] \mathrm{ATP}$-labeled synthetic oligonucleotide corresponding to $18 \mathrm{~S}$ ribosomal RNA (32). The results were analyzed by autoradiography and densitometry (ImageQuant; Molecular Dynamics, Sunnyvale CA). Paraffin sections (10 $\mu \mathrm{m}$ thick) of AD and control brains were hybridized $(15,16)$ with antisense and sense (negative control) AD7c-NTP cRNA probes generated from complete cDNA templates linearized with Kpn1 or Xho1. The probes were labeled with [11-digoxigenin]UTP using SP6- or T7 DNAdependent RNA polymerase (29). Specifically bound probe was detected with alkaline phosphatase-conjugated sheep $\mathrm{F}(\mathrm{ab} 9)_{2}$ antidigoxigenin (Boehringer Mannheim Biochemicals, Indianapolis, IN) and X-phosphate/5-bromo-4-chloro-3-indolyl-phosphate/nitro-bluetetrazolium-chloride. The probe specificity was confirmed by Northern blot analysis of brain using identical cRNA probes labeled with $\left[\alpha^{32} \mathrm{P}\right] \mathrm{UTP}$.

Reverse transcriptase polymerase chain reaction amplification (RT-PCR) studies. Samples of total RNA $(2 \mu \mathrm{g})$ isolated from human brain were reverse transcribed using random hexamer primers (29) and Superscript reverse transcriptase (GIBCO BRL, Gaithersburg, MD). The cDNA products $(10 \%)$ were subjected to PCR amplification to detect AD7c-NTP sequences using the primers: (459-480) 5' TGTCCCACTCTTACCCAGGATG and (849-826) 5' AAGCAGGCAGATCACAAGGTCCAG. $\beta$-actin control primers (33) (5' AATGGATGACGATATCGCTG; 5'-ATGAGGTAGTCTGCAGGT) were incorporated into all studies. The PCR products were ligated into PCRII TA cloning vectors (Invitrogen Corp.). The nucleotide sequences of clones isolated from $6 \mathrm{AD}$ and 5 aged control brain samples were determined by the dideoxy chain termination method (29).

Immunodetection of AD7c-NTP expression. Western immunoblotting studies $(29,30)$ were performed using protein extracts $(60 \mu \mathrm{g}$ samples) generated from postmortem human frontal and temporal lobe tissue, and various non-CNS tissues. In addition, $40 \mu \mathrm{l}$ samples of postmortem and antemortem cerebrospinal fluid were evaluated by Western blot analysis. The blots were probed with rabbit polyclonal (1:800) or N3I4, N2U6, or N2J1 mouse monoclonal $(5 \mu \mathrm{g} / \mathrm{ml})$ antibodies prepared against recombinant AD7c-NTP (30). Antibody binding was detected with horseradish peroxidase-conjugated secondary antibody diluted 1:40,000 (Pierce Chemical Co., Rockford, IL), and Supersignal enhanced chemiluminescence reagents (Pierce Chemical Co.). The levels of AD7c-NTP expression were quantified by volume densitometric scanning of the autoradiograms (ImageQuant; Molecular Dynamics). Cellular localization of AD7c-NTP immunoreactivity was demonstrated in paraffin-embedded histological sections of frontal (Brodmann Area 11) and temporal (Brodmann Area 21) lobe from AD and age-matched control brains. The sections were immunostained by the avidin-biotin horseradish peroxidase complex method $(15,16)$ using the N2T8 AD7c-NTP mAb. Adjacent sections were immunostained with $\mathrm{mAb}$ to glial fibrillary acidic protein as a positive control, and with $\mathrm{mAb}$ to Dengue virus as a negative control.

Source of CSF. CSF specimens were obtained from five sources: (a) ambulatory patients with possible or probable $\mathrm{AD}$ who had been 
evaluated and followed in the MGH Memory Disorders Unit; $(b)$ ambulatory patients with Parkinson's disease (PD) evaluated and treated in the MGH Movement Disorders Clinic; $(c)$ patients evaluated and treated at the MGH for chronic or relapsing multiple sclerosis (MS) or other inflammatory CNS diseases; $(d)$ nondemented MGH controls evaluated for pain or symptoms referable to neurological or neuropsychiatric disorders, e.g., cervical radiculopathy, seizure disorder, peripheral neuropathy, schizophrenia, and psychotic depression; and $(e)$ deceased patients with postmortem confirmed AD or histologically intact normal brains from the Ramsey Alzheimer's Treatment and Research Center. The PD patients represented neurodegenerative disease controls, while the MS patients served as nonneurodegenerative neurological disease controls.

CSF samples from the MGH ambulatory patients with early (possible or probable) AD or established PD were obtained between 1979 and 1992. The AD and PD patients were subjected to detailed neurological, neurobehavioral, and cognitive assessments, including Blessed Dementia Scale Scores (BDSS), Mini-Mental Status Examinations (MMSE), electroencephalography, and computed tomographic or magnetic resonance imaging studies of the brain. Several control patients also had neuropsychiatric examinations with cognitive testing. Follow-up evaluations conducted over the subsequent years included neurological examinations and cognitive performance tests, e.g., BDSS and MMSE. The clinical diagnosis of probable AD was rendered using criteria established by the National Institute of Neurological and Communicative Disorders and Stroke/Alzheimer's Disease and Related Disorders Association (NINDS/ADRDA) (34). Among those who died, postmortem examinations were obtained to confirm the diagnosis of AD. The diagnoses of PD and MS were made based upon the clinical course and sequential examinations.

The clinical (antemortem) CSF samples used in this study represented discarded lumbar puncture specimens obtained for diagnosis or use in previous informed consent research protocols approved by the human studies committee at the MGH. Postmortem CSF was harvested from the lateral ventricles. All CSF samples were clear, colorless, nonhemolyzed, and stored at $-80^{\circ} \mathrm{C}$ until used. The level of protein present in CSF varied from 0.15 to $0.45 \mathrm{mg} / \mathrm{ml}$ with the majority of samples in the range of 0.3 to $0.4 \mathrm{ml}$. Western blot analysis was used to characterize the molecular mass of AD7c-NTP in both antemortem and postmortem CSF specimens $(15,20)$. In addition, the molecular mass of AD7c-NTP was analyzed in several samples by high performance liquid chromatography (HPLC) (size exclusion column: Supelco TSK, G2000SW, flow rate $1 \mathrm{ml} / \mathrm{min}$ ). In brief, $100 \mu \mathrm{l}$ of CSF were passed through the column along with molecular mass standards and $50(0.5 \mathrm{ml})$ fractions were collected. Each fraction was analyzed for AD7c-NTP immunoreactivity by two ELSIAs that employ the N3I4 or N3C11 as the capture antibodies linked to the solid phase support followed by detection with polyclonal antibodies prepared against the recombinant protein. These results were confirmed by capillary electrophoresis (Bio-Rad cartridge 1423050) based on size exclusion of the fractions that contained AD7c-NTP immunoreactivity.

ELSIA to measure AD7c-NTP concentrations in CSF. The concentration of AD7c-NTP in CSF was determined by an ELSIA that was developed after exploring approximately 100 different monoclonal and polyclonal antibody combinations. ${ }^{2}$ The N3I4 monoclonal antibody was used to capture AD7c-NTP-immunoreactive proteins, and a rabbit polyclonal antibody (ADRI) was used to detect bound proteins. ${ }^{2}$ Both N3I4 and ADRI were generated with recombinant AD7c-NTP (30), and affinity purified on Protein A/G columns (29). Antibody binding specificity to recombinant AD7c-NTP and not to nonrelevant proteins such as human albumin or gamma globulin was demonstrated in direct binding radioimmunoassays $(35,36)$. The AD7c-NTP ELSIA was highly sensitive (30 pg), reproducible (C.V. < $10 \%)$, and linear up to $100 \mathrm{ng} / \mathrm{ml}\left(r^{2}>0.9\right)$ with a recovery rate of more than $90 \%$ based on additions of AD7c-NTP recombinant protein. Duplicate CSF samples $(100 \mu \mathrm{l})$ were analyzed under code and the values obtained were in the linear range of the standard curve. In addition, there was no difference in the results of AD7c-NTP levels as expressed either as $\mathrm{ng} / \mathrm{ml}$ of CSF or $\mathrm{ng} / \mu \mathrm{g}$ protein in CSF. The clinical records were reviewed without knowledge of the assay results.

Data analysis. The data were analyzed using descriptive statistics to determine group mean $( \pm \mathrm{SD}$ and $95 \%$ confidence interval limits [CIL]) age, BDSS, and CSF AD7c-NTP levels, and gender ratios. For the postmortem component of the study, between-group comparisons were made using Student's $t$ and Chi-square tests. In addition, multiple linear regression analysis was used to assess potential correlations between CSF AD7c-NTP levels and diagnosis, age ( $>50 \mathrm{yr}$ ), or gender. For the clinical (antemortem) component of the study, intergroup differences in mean age, BDSS, and CSF AD7c-NTP levels were analyzed by analysis of variance and post hoc Duncan and Fisher's LSD tests. Multiple linear regression analysis was used to assess potential correlations between CSF AD7c-NTP levels and diagnosis, age ( $>50 \mathrm{yr})$, BDSS, or gender. The data analysis was performed using the Number Cruncher Statistical System software, version 6.5 (JL Hintze, Kaysville, Utah).

In vitro expression studies. The AD7c-NTP cDNA was ligated into the pcDNA3 mammalian expression vector which contains a CMV promoter (Invitrogen Corp.). SH-Sy5y (37) and PNET2 (38) neuronal cells were transfected with either pcDNA3-AD7c-NTP or pcDNA3 (empty vector, negative control), plus a luciferase gene reporter construct (pcDNA3-Luc) using Cellfectin reagent (GIBCO BRL). Transfected cells were selected with G418, and stably transfected cell lines were examined for growth properties, morphology, and expression of AD7c-NTP. Cell growth was assessed by measuring $\left[{ }^{3} \mathrm{H}\right]$ thymidine incorporation into DNA, and determining the density of viable cells in the cultures. AD7c-NTP expression was evaluated by Western blot analysis and immunocytochemical staining with the N3I4 mAb. The immunostaining studies were performed with cells grown in 4-well Lab-Tek tissue culture chambers (Nunc, Inc., Naperville, IL).

\section{Results}

Characteristics of the AD7c-NTP cDNA isolated from an $A D$ brain library. The AD7c-NTP cDNA contains 1442 nucleotides and begins with an oligo-dT track as shown in Fig. 1. The nucleotide sequence contains an 1125-nucleotide open reading frame starting with the putative first AUG codon, and a 302-nucleotide untranslated sequence that contains an AATAAA polyadenylation signal (Fig. 1). Bestfit and GAP analyses revealed the presence of four Alu-type sequences embedded in the open reading frame (nucleotides 1-170, 423$593,595-765$, and 898-1068), and a near-duplication (85\% identical) of the first 450 nucleotides starting at nucleotide 898 . The translated 375 amino acid sequence has a predicted molecular weight of 41,718 and estimated $\mathrm{pI}$ of 9.89 , and is rich in Ser $(11.7 \%)$ and Pro $(8.8 \%)$ residues. Kyte-Doolittle and Chou-Fasman hydrophilicity and Hopp-Woods surface probability profiles predict a 15 amino acid hydrophobic leader sequence, and seven putative membrane-spanning regions. Corresponding with the organization of the cDNA, subsequent analysis of the protein revealed four $83-91 \%$ identical repeated (once or twice) antigenic domains between 9 and 23 amino acids in length beginning at residues: No.s 1-31, 175 and 277; No.s 2-121 and 334; No.s 3-208 and 308; and No.s 4-232 and 332. Protein subsequence analysis demonstrated 17 cAMP, calmodulin-dependent protein kinase II, protein kinase $\mathrm{C}$, or glycogen synthase kinase 3 phosphorylation sites, and one myristylation site. In addition, two serine/threonine kinase protein domains (residues 6-48, and 272-294) were identified. Since the AD7c-NTP cDNA exhibits no significant 
1 tettettttgag ATG GAG T"TT TCG CTC TTG TTG CCC AGg CTG GAG TGC AAT GGC GCA ATC 62

$\begin{array}{llllllllllllllllll}\mathrm{M} & \mathrm{E} & \mathrm{F} & \mathrm{S} & L & L & L & P & R & L & E & C & N & G & \boldsymbol{A} & \boldsymbol{I} & 16\end{array}$

63 TCA GCT CAC CGC AAC CTC CGC CTC CCG GGT TCA AGC GAT TCT CCT GCC TCA GCC TCC CCA 122 $\begin{array}{llllllllllllllllllllllll}17 & \boldsymbol{S} & \mathbf{A} & H & R & N & L & R & L & \mathrm{P} & \mathrm{G} & \mathrm{S} & \mathrm{S} & \mathrm{D} & \text { () } & \mathrm{P} & \mathrm{A} & \mathrm{S} & \mathrm{A} & \text { () } & \mathrm{P} & 36\end{array}$

123 GTA GCT GGg ATT ACA GGC ATg TGC ACC CAC GCT CGg CTA ATT TTG TAT TTT TTT TTA GTA 182

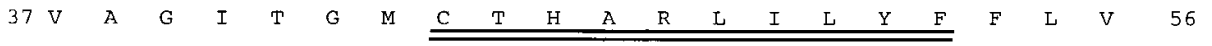

183 GAG ATG GAG TTT CTC CAT GTI GGT CAG GCT GGT CTC GAA CTC CCG ACC TCA GAT GAT CCC 242

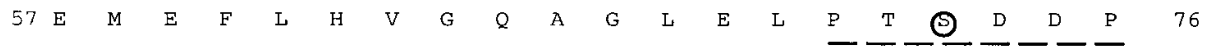

243 TCC GTC TCG GCC TCC CAA AGT GCT AGA TAC AGG ACT GGC CAC CAT GCC CGG CTC TGC CTG 302 $\begin{array}{lllllllllllllllllllll}77 \mathrm{Q} & \mathrm{V} & \text { (S) } & \mathrm{A} & \mathrm{S} & \mathrm{Q} & \text { (S) } & \mathrm{A} & \mathrm{R} & \mathrm{Y} & \mathrm{R} & \mathrm{P} & \mathrm{G} & \mathrm{H} & \mathrm{H} & \mathrm{A} & \mathrm{R} & \mathrm{L} & \mathrm{C} & \mathrm{L} & 96\end{array}$ - - - - - - - - - - - - - - - - -

303 GCT AAT TTT TGT GGT AGA AAC AGG GTT TCA CTG ATG TGC CCA AGC TGG TCT CCT GAG CTC 362 $\begin{array}{llllllllllllllllllllll}97 & A & N & F & C & G & R & N & R & V & S & \text { L } & M & C & \text { P } & \text { S } & \text { W } & \text { S } & \text { P } & \text { E } & \text { L } & 116\end{array}$ 363 AAG CAG TCC ACC TGC CTC AGC CTC CCA AAG TGC TGG GAT TAC AGg CGT GCA GCC GTG CCT 422 $\begin{array}{llllllllllllllllllllll}117 & \mathrm{~K} & \mathrm{Q} & \mathrm{O} & \mathrm{T} & \mathrm{C} & \mathrm{L} & \mathrm{S} & \mathrm{L} & \mathrm{P} & \mathrm{K} & \mathrm{C} & \mathrm{W} & \mathrm{D} & \mathrm{Y} & \mathrm{R} & \mathrm{R} & \mathrm{A} & \mathrm{V} & \mathrm{P} & 136\end{array}$ 423 GGC CTT TTT ATT TTA TTT TTT TTA AGA CAC AGG TGT CAC ACT CTT ACC CAG EAT CAA CTG 482

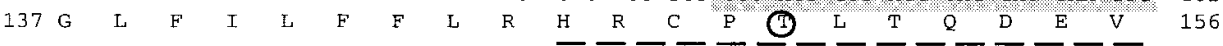
483 CAG TGG TET CAT CAC ACC TCA CTG CAG CCT TCA ACT CCT GAC ATC AAG CAT CCT CeT CAC 542

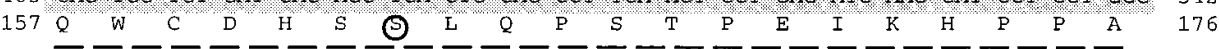
3. TCA GCC TCC CAA GTA GCT CGC ACC AAA GAC ATC CAC CAC TAC ACC TGC CTA ATT TTT ATT 602

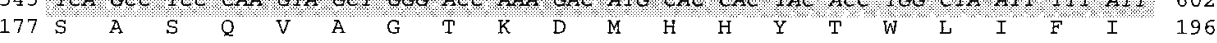

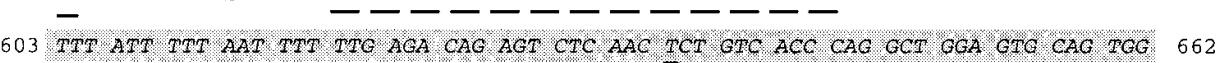
$\begin{array}{llllllllllllllllllllllllll}197 & \text { F } & \text { I } & \text { F } & \text { N } & \text { F } & \text { L } & \text { R } & \text { Q } & \text { S } & \text { L } & \text { N } & \text { (S) } & \text { V } & \text { T } & \text { Q } & \text { A } & \text { G } & \text { V } & \text { Q } & \text { W } & 216\end{array}$

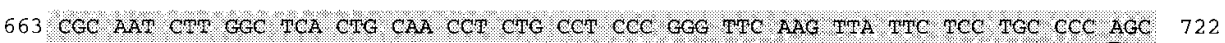
$\begin{array}{lllllllllllllllllllllllll}217 & \text { R } & \text { N } & \text { L } & \text { G } & \text { S } & \text { L } & \text { Q } & \text { P } & \text { L } & \text { P } & \text { P } & G & \text { F } & \text { K } & \text { L } & \text { F } & \text { S } & \text { C } & \text { P } & \text { (S) } & 236\end{array}$

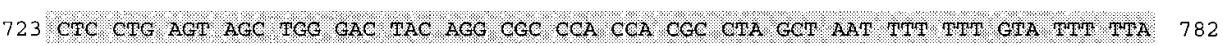

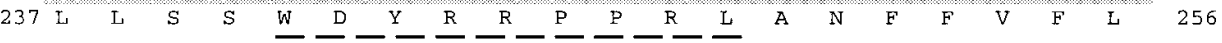

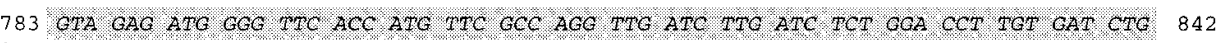

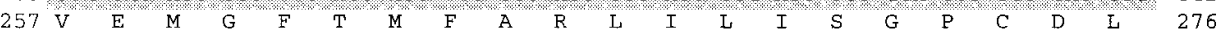
843 CCT GCC ICG GCC TCC CAA AGT GCT GGG ATT ACA GGC GTG AGC CAC CAC GCC CGG CTI ATT 902

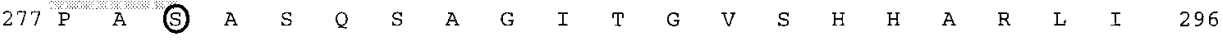

903 TTT AAT TTT TGT TTG TTT GAA ATG GAA TCT CAC TCT GTT ACC CAG GCT GGA GTG CAA TGG 962 $\begin{array}{lllllllllllllllllllllll}297 & \mathrm{~F} & \mathrm{~N} & \mathrm{~F} & \mathrm{C} & \mathrm{L} & \mathrm{F} & \mathrm{E} & \mathrm{M} & \mathrm{E} & \mathrm{S} & \mathrm{H} & \mathrm{S} & \mathrm{V} & \mathrm{T} & \mathrm{Q} & \mathrm{A} & \mathrm{G} & \mathrm{V} & \mathrm{Q} & \mathrm{W} & 316\end{array}$

963 CCA AAT CTC GGC TCA CTG CAA CCT CTG CCT CCC GGG CTC AAG CGA TTC TCC TGT CTC AGC 1022 $\begin{array}{llllllllllllllllllllll}317 & \text { P } & \text { N } & \text { L } & \text { G } & \text { S } & \text { L } & \text { Q } & \text { P } & \text { L } & \text { P } & \text { P } & \text { G } & \text { L } & \text { K } & \text { R } & \text { F } & \text { S } & \text { C } & \text { L } & \text { S } & 336\end{array}$

1023 CTC CCA AGC AGC TGg GAT TAC GGG CAC CTG CCA CCA CAC CCC GCT AAT TTT TGT ATT TTC 1082

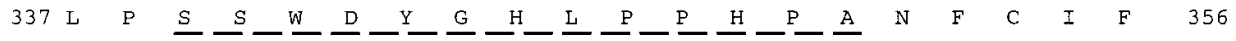

1083 ATT AGA GGC GGG GTT TCA CCA TAT TTG TCA GGC TGG TCT CAA ACT CCT GAC CTC AGG tgac 1143 $\begin{array}{lllllllllllllllllllllll}357 & \text { I } & \text { R } & \text { G } & \text { G } & \text { V } & \text { G } & \text { F } & \text { Y } & \text { L } & \text { S } & \text { G } & \text { W } & \text { S } & \text { Q } & \text { (P) } & \text { P } & \text { D } & \text { L } & \text { R } & & 375\end{array}$

1144 ccacctgcctcagccttccaaagtgctgggattacaggcgtgagccacctcacccagccggctaatttagataaaaaat 1223 1224 atgtagcaatggggggtcttgctatgttgcccaggctggtctcaaacttctggcttcatgcaatccttccaaatgagcca 1303 1304 caacacccagccagtcacatttttaaacagttacatctttattttagtatactagaaagtaatacaataacatgtcaa 1383

1442
Figure 1. Nucleotide and translated amino acid sequence of the AD7c-NTP cDNA (GenBank \#AF010144). The shaded region corresponds to the nucleic acid sequences detected in six AD brains by RT-PCR analysis of mRNA. The cDNA exhibits significant homology with Alu genes. The open reading frame begins with a putative first methionine codon. The translated amino acid sequence encodes a 41.7$\mathrm{kD}$ protein with a hydrophobic leader sequence (italics) followed by a myristylation motif (bold italics) and potential AI cleavage site. That same region (underlined italics) exhibits significant homology with the insulin/IGF-1 chimeric receptor. There are 17 potential glycogen synthase kinase-3, protein kinase $\mathrm{C}$, or cAMP or Ca-dependent kinase II phosphorylation motifs (circled) and one TGF $\beta$ motif (double-underline). There are seven putative membrane spanning regions (dashed underline). primary sequence homology with human pancreatic thread protein (28), the cross-reactivity of polyclonal antibodies with AD7c-NTP molecule probably occurs through conformational epitopes.

The in vitro translated protein and pTrcHis-AD7c-NTP recombinant protein purified by metal chelate chromatography and cleaved from the fusion partner had molecular masses of $\sim 39-42 \mathrm{kD}$ by SDS-PAGE (Fig. $2 A$ ) or Western blot analysis (Fig. $2 B$ ). In addition, in BOSC cells transfected with the AD7c-NTP cDNA ligated into the pcDNA3 vector (Invitrogen Corp.), a single $\sim 39-42-\mathrm{kD}$ protein was detected by Western blot analysis using the N3I4 mAb (Fig. $2 C$ ). No immunoreactivity to AD7c-NTP was detected using preimmune rabbit sera, nonrelevant rabbit polyclonal antibodies to GAP43 , or nonrelevant mAbs to Dengue virus (data not shown) or FB50 (Fig. $2 B$ ).

$A D 7 c-N T P$ mRNA expression in $A D$ and aged control brains. In Northern blot hybridization studies, AD7c-NTP cDNA probes detected $1.4 \mathrm{kB}$ and $0.9 \mathrm{kB}$ (weak) mRNA transcripts in adult human frontal and temporal lobe tissue, but not pancreas, kidney, liver, spleen, gastrointestinal tract (various regions) ovaries, fallopian tubes, uterus, thyroid, lung, skeletal muscle, testis, and thymus (data not shown). With values normalized to $18 \mathrm{~S}$ RNA signals to correct for differences in loading, densitometric analysis of nonsaturated autoradiograms revealed significantly higher mean $(7.34 \pm 0.65$ versus $4.04 \pm 0.39)$ 

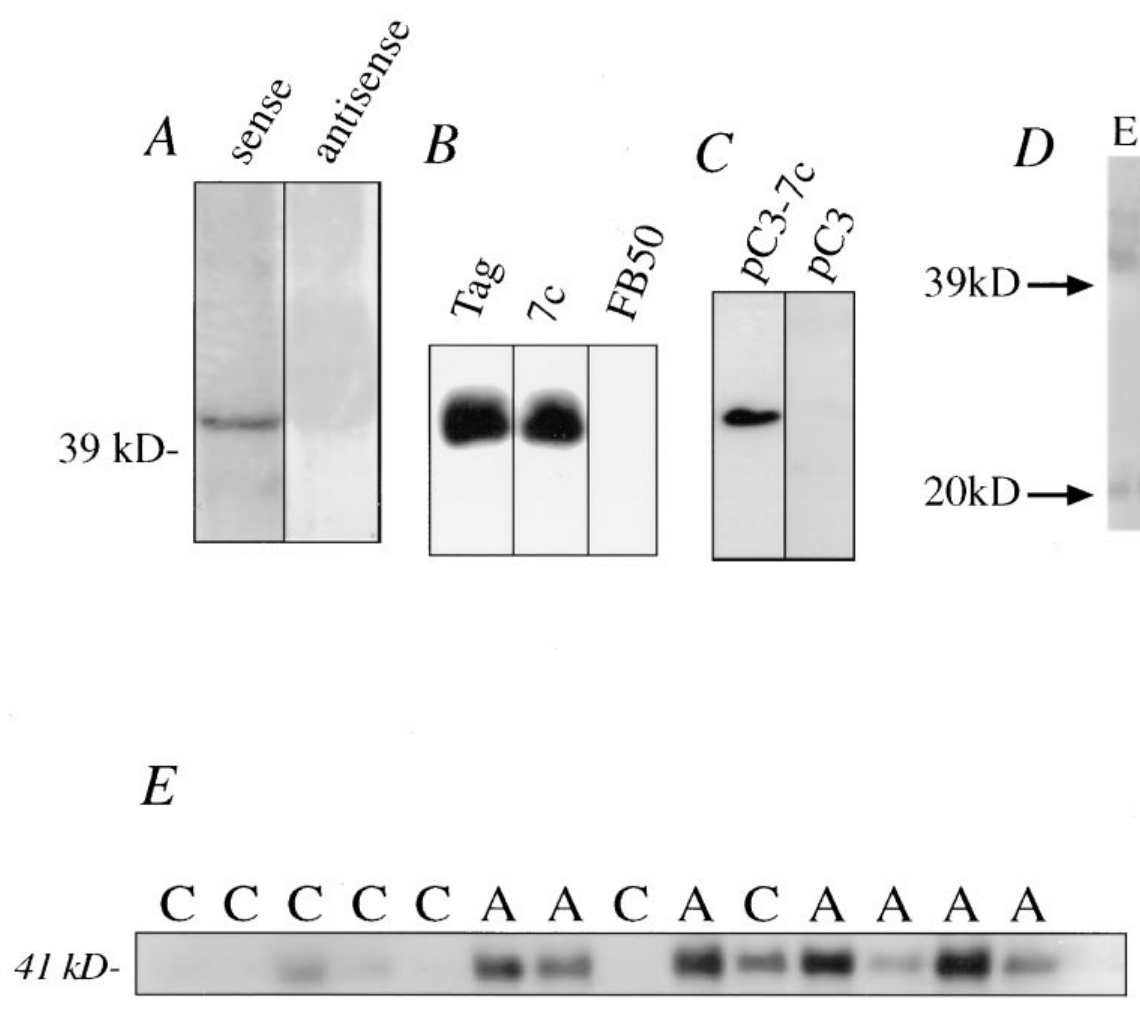
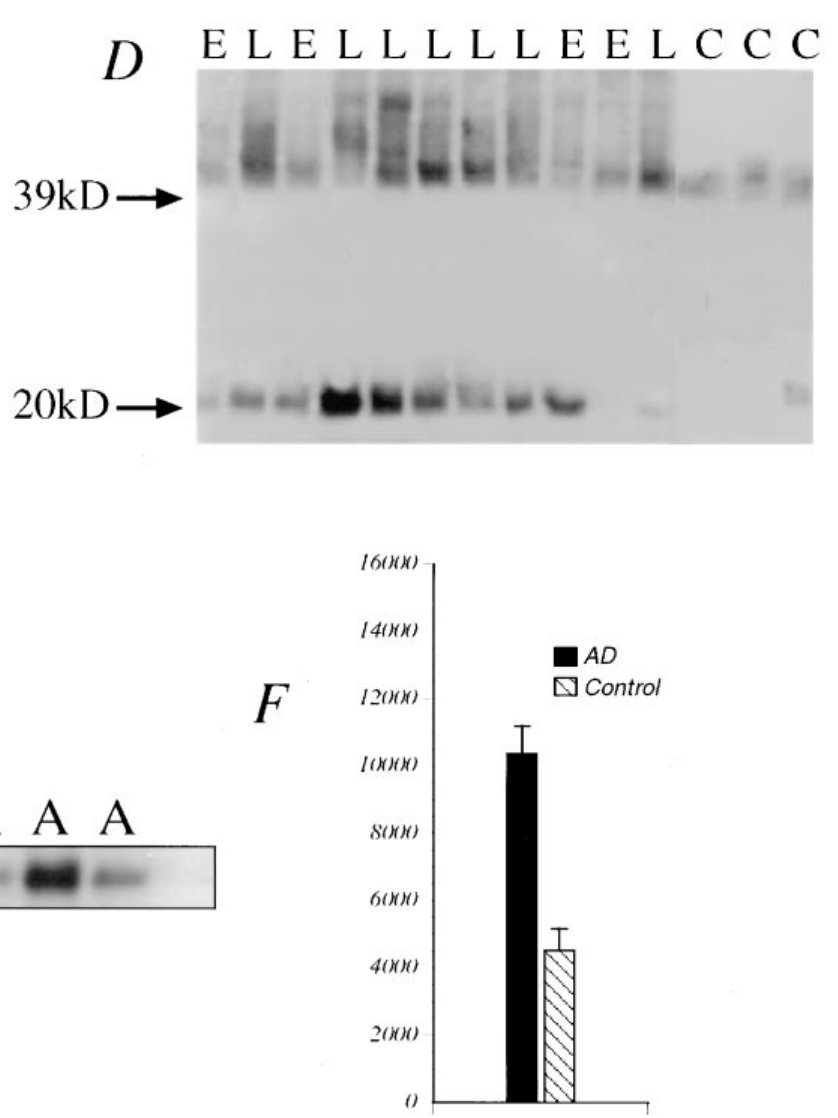

Figure 2. AD7c-NTP expression in vitro and in vivo. $(A)\left[{ }^{35}\right.$ S $]$ Methionine-labeled recombinant protein detected by in vitro translation using sense strand cRNA transcripts. $(B)$ Western blot analysis of purified recombinant protein demonstrating specific immunoreactivity with the Tag and N3I4 AD7c-NTP mAbs, but not with nonrelevant FB50 mAb. (C) Western blot analysis of BOSC cells stably transfected with pcDNA3AD7c-NTP or pcDNA3 (empty vector). The blots were probed with the N3I4 AD7c-NTP antibody. ( $D$ ) Western blot autoradiograms demonstrating higher levels of the $\sim 41-45-\mathrm{kD}$ and $18-21-\mathrm{kD}$ AD7c-NTP proteins in late, end-stage $(L)$ AD compared with early $(E)$, i.e., possible or probable $\mathrm{AD}$ frontal lobe tissue using the N2U6 mAb. The possible/probable AD group included individuals with abundant senile plaques, but insufficient neurofibrillary tangles to fulfill the CERAD (31) criteria for definite AD. The late AD cases all had end-stage definite AD dementia with abundant neurofibrillary tangles, neuritic plaques, and neuropil threads. Normal aged control $(C)$ brains are included for comparison. The tissue samples were homogenized in buffer containing $1 \mathrm{mM} \mathrm{Na}_{4} \mathrm{P}_{2} \mathrm{O}_{7}$ and $2 \mathrm{mM} \mathrm{Na}_{2} \mathrm{VO}_{4}$ to preserve protein phosphorylation. Note the clusters of three or four bands between $\sim 41$ and $\sim 45 \mathrm{kD}$. (E) Increased levels of the $\sim 41$-kD AD7c-NTP protein in AD $(A)$ compared with aged control $(C)$ ventricular fluid samples demonstrated by Western blot analysis using the N3I4 mAb. $(F)$ Increased levels (arbitrary densitometry units) of the N3I4-immunoreactive $\sim 41-\mathrm{kD}$ AD7c-NTP protein in AD relative to age-matched control frontal lobe tissue with the mean \pm SEM for each group. Similar results were obtained for temporal lobe specimens.

levels of the 1.4-kB AD7c-NTP transcripts in AD compared with normal aged control brains $(P<0.01)$. Expression of AD7c-NTP mRNA in human brain was verified by RT-PCR amplification of RNA isolated from six AD and five aged control brains (frontal lobe). The expected 390 nucleotide PCR product was obtained with all samples (data not shown). The specificity of the PCR products was demonstrated by Southern blot analysis using $\left[{ }^{32} \mathrm{P}\right]$-labeled oligonucleotide probes corresponding to internal sequences, and by determining that the nucleic acid sequences of the 390-nucleotide PCR products cloned from six AD brains were identical to the sequence corresponding to the shaded region in Fig. 1.

$A D 7 c-N T P$ protein expression in $A D$ and aged control brains. Western blot analysis using the N3I4 AD7c-NTP mAbs (30) detected $\sim 41-\mathrm{kD}$ proteins in both $\mathrm{AD}$ and aged control frontal lobe tissues (data not shown). Densitometric analysis of the autoradiograms revealed higher levels of the $\sim 41-\mathrm{kD}$ AD7c-NTP protein in most AD relative to aged control samples, and Student's $t$ test analysis demonstrated the group mean differences to be statistically significant $(\mathrm{t}=9.5$; 19 df; $P<0.0001$ ) (Fig. $2 F$ ). Similar results were obtained with temporal lobe tissue samples from the same brains (data not shown). When brain proteins were extracted in buffer containing $1 \mathrm{mM} \mathrm{Na} \mathrm{P}_{2} \mathrm{O}_{7}$ and $2 \mathrm{mM} \mathrm{Na} \mathrm{VO}_{4}$ to minimize protein dephosphorylation, $\sim 41-45-\mathrm{kD}$ rather than $\sim 41-\mathrm{kD}$ AD7c-NTP species were detected with the N2J1 (data not shown) and N2U6 mAbs (Fig. 2 D). In addition, N2J1 (data not shown) and N2U6 mAbs detected $\sim 18-21-\mathrm{kD}$ AD7c-NTP proteins as shown in Fig. $2 \mathrm{D}$, independent of whether $1 \mathrm{mM} \mathrm{Na}_{4} \mathrm{P}_{2} \mathrm{O}_{7}$ and $2 \mathrm{mM} \mathrm{Na}_{2} \mathrm{VO}_{4}$ were included in the extraction buffer. Expres- 

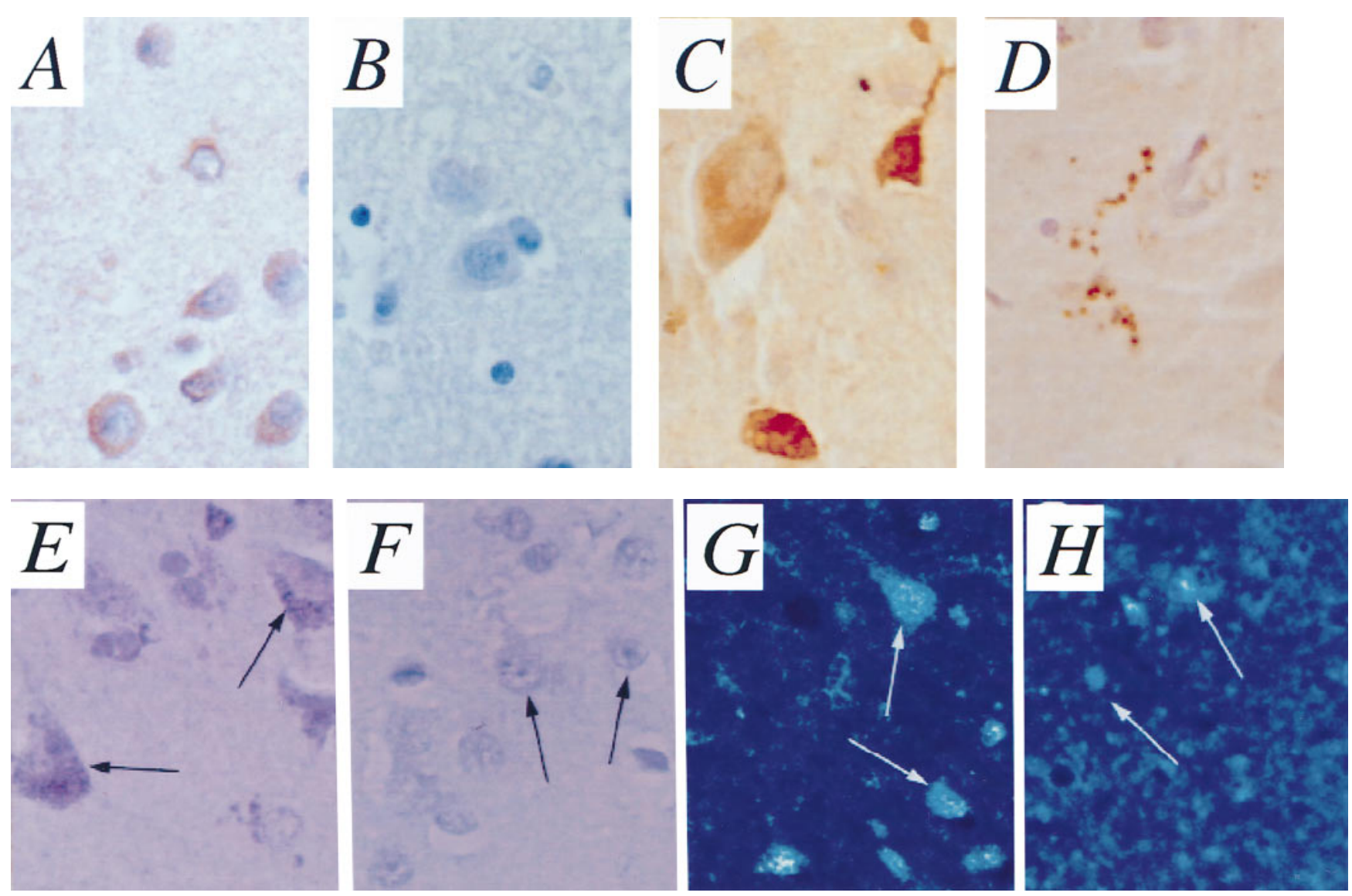

Figure 3. $(A-D)$ Increased and altered AD7c-NTP immunoreactivity in AD relative to aged control frontal cortex neurons demonstrated by immunohistochemical staining using the N2T8 mAb. Immunoreactivity was revealed with diaminobenzidine which yields a brown immunoprecipitate. Increased AD7c-NTP immunoreactivity was observed in AD $(A)$ relative to aged control $(B)$ cortical neurons, as well as in degenerating neurons $(C)$ and abnormal neuritic processes $(D)$ in AD cerebral cortex. ( $E$ and $F$ ) Brightfield photomicrographs of in situ hybridization results using antisense $(E)$ or sense $(F)$; negative control digoxigenin-labeled cRNA probes. Arrows indicate examples of neurons and purple grains represent positive hybridization signals. $(G$ and $H$ ) Dark-field photomicrographs of in situ hybridization results demonstrating more intense labeling (white grains) in $\mathrm{AD}(G)$ than in aged control $(H)$ cortical neurons (arrows) in the frontal lobe.

sion of $\sim 18-21-\mathrm{kD}$ AD7c-NTP-immunoreactive proteins was also increased in AD brains (30), and preliminary studies suggest that these molecules are encoded by a distinct mRNA that shares significant nucleic acid sequence homology with AD7cNTP (de la Monte et al., unpublished observation). In a small series, comparisons between early (possible or probable) and late end-stage or definite $\mathrm{AD}$ revealed generally higher levels of both the $\sim 41-45-\mathrm{kD}$ and $\sim 18-21-\mathrm{kD}$ AD7c-NTP-immunoreactive proteins in brains with end-stage disease (Fig. $2 D$ ). Using the N3I4 antibody, Western blot analysis detected $\sim 41$ $\mathrm{kD}$ AD7c-NTP molecules in postmortem CSF, and higher levels in AD relative to aged control samples (Fig. 2 E). Quantitative analysis of AD7c-NTP levels measured in CSF by ELSIA are presented below. Western blot analysis of noncentral nervous system tissues revealed no specific binding with any of the AD7c-NTP mAbs (data not shown).

Cellular localization of AD7c-NTP protein and $m R N A$ in human brain. Immunohistochemical staining studies with N2T8 $\mathrm{mAb}$ localized AD7c-NTP immunoreactivity in neurons, neuropil fibers, white matter fibers, and irregular neuritic processes in AD brains (Fig. 3, $A, C$, and $D$ ). In contrast, there was very low level or absent immunoreactivity in aged control brains immunostained with the N2T8 mAb (Fig. 3 B). In situ hybridization studies demonstrated AD7c-NTP-related mRNA transcripts in frontal (Brodmann Area 11) and temporal (Brodmann Area 21) cortex neurons in both $\mathrm{AD}$ and aged control brains (Fig. 3, E, $G$, and $H$ ). However, dark-field microscopy revealed strikingly elevated levels of AD7c-NTP mRNA expression in both temporal and frontal cortex neurons in $\mathrm{AD}$ (Fig. $3 G$ ) relative to aged control brains (Fig. $3 H$ ), corresponding with the immunohistochemical staining results. Low levels of AD7c-NTP mRNA transcripts were also detected in cortical and white matter glial cells in AD. AD7c-NTP mRNA transcripts were not detected in cerebral blood vessels, and specific hybridization signals were not observed in any of the specimens hybridized with digoxigenin-labeled sense strand cRNA probes.

Characterization of AD7c-NTP in CSF. Next, we studied the characteristics of AD7c-NTP molecules in CSF. Fig. 4 demonstrates that a single molecular mass species of $41 \mathrm{kD}$ was present in antemortem CSF as analyzed by HPLC fractionation of CSF followed by immunologic analysis of each fraction. In this study, we used two ELSIAs that employ mAbs that recognized distinct and separate epitopes on the recombinant 41-kD AD7c-NTP protein. Thus, in contrast to the multiple molecular mass forms of approximately 41-44 and 18-21 


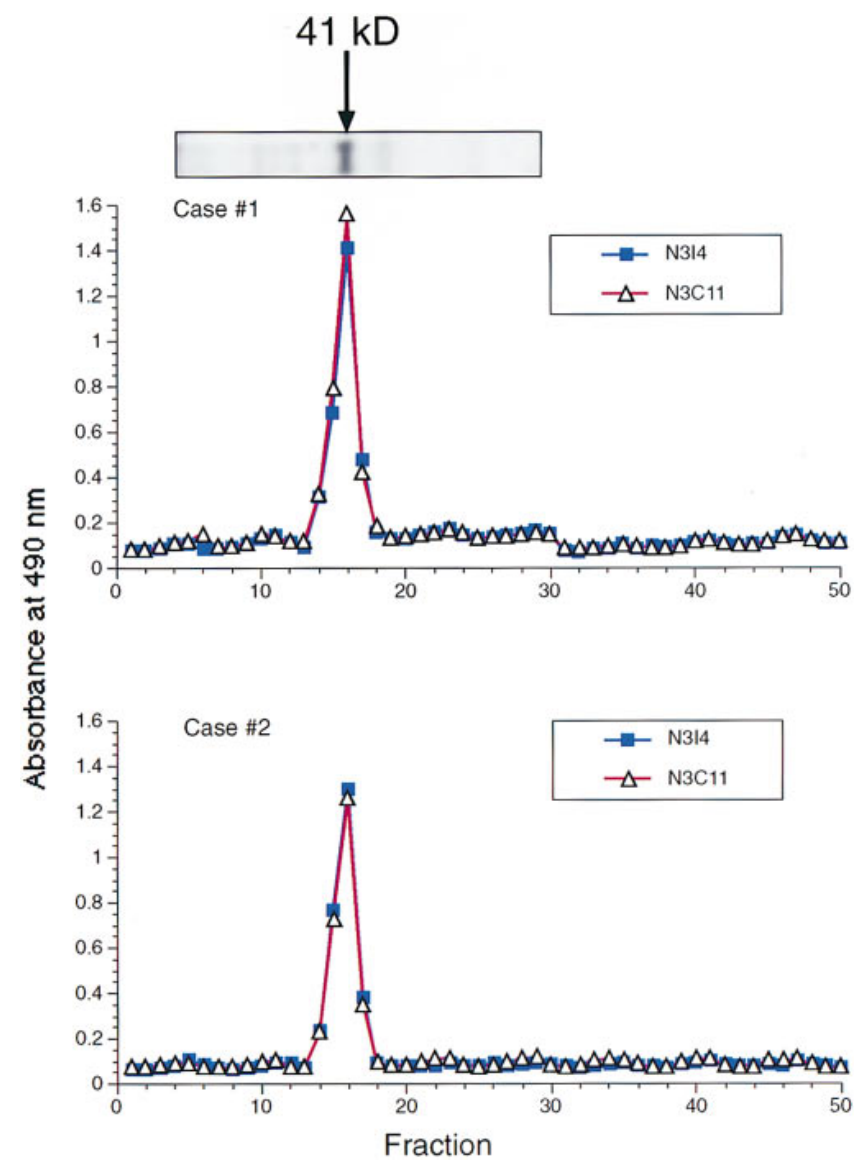

Figure 4. Characterization of the molecular size of AD7c-NTP protein in AD CSF samples. The top represents a Western blot of CSF with the N3I4 mAb. In this study, CSF was fractionated by HPLC (size exclusion) and each fraction $(n=50)$ was analyzed by two different ELSIAs using N3I4 and N3C11 mAbs as capture antibodies linked to the solid phase support and polyclonal as detection antibodies. These antibodies had been prepared against the $41-\mathrm{kD}$ recombinant AD7c-NTP protein. It is apparent that there was only one $41-\mathrm{kD}$ molecular mass species of AD7c-NTP with such defined immunoreactivity present in these two CSF samples.

$\mathrm{kD}$ identified in AD brain tissue by Western blot analysis (Fig. $2 \mathrm{D}$ ), the dominant molecule found in CSF derived from individuals with early (possible or probable) AD appeared as a single $41-k D$ protein species.

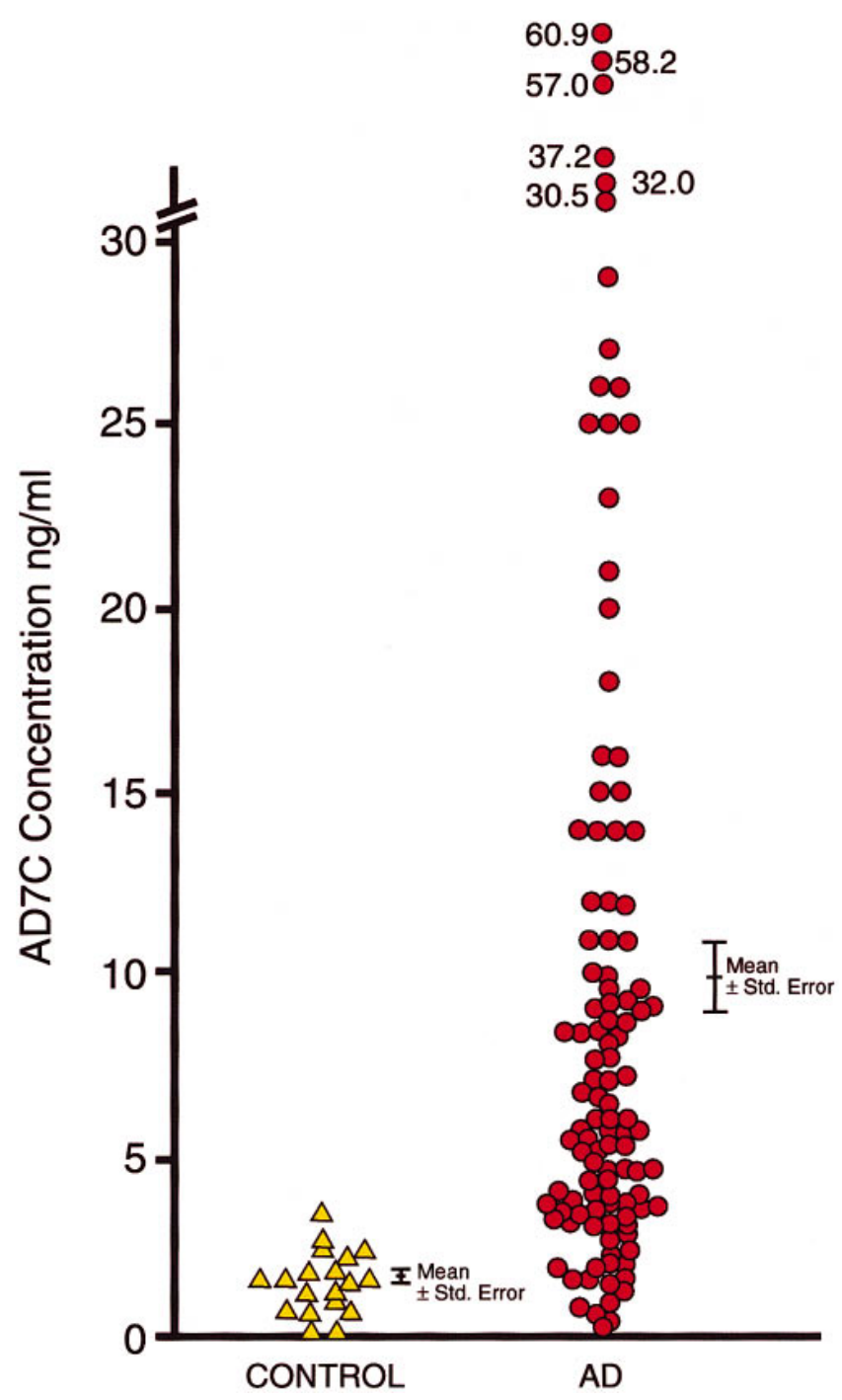

Figure 5. Distribution of AD7c-NTP concentrations $(\mathrm{ng} / \mathrm{ml})$ in postmortem $\operatorname{AD}(n=121)$ and aged control $(n=19)$ CSF samples. AD7c-NTP levels were measured by a forward sandwich ELSIA using N3I4 as the capture antibody and polyclonal ADRI as the detection antibody. Note that $84 \%$ of the AD samples contained $>3 \mathrm{ng} / \mathrm{ml}$ of AD7c-NTP protein.

Table I. Population Profile and AD7c-NTP Levels in Postmortem and Clinical Cerebrospinal Fluid

\begin{tabular}{|c|c|c|c|c|c|}
\hline Group & No. cases & Age $(\mathrm{yr})^{*}$ & Male:Female No. (\%) & BDSS* & $\operatorname{AD} 7 \mathrm{c}-\mathrm{NTP}(\mathrm{ng} / \mathrm{ml})^{*}$ \\
\hline \multicolumn{6}{|l|}{ Postmortem study } \\
\hline Alzheimer's disease & 121 & $77.3 \pm 6.5$ & $42(35): 79(65)$ & ND & $9.2 \pm 8.2^{\ddagger}$ \\
\hline Control & 19 & $72.5 \pm 6.8$ & $9(47): 10(53)$ & ND & $1.6 \pm 0.9$ \\
\hline \multicolumn{6}{|l|}{ Clinical study } \\
\hline Early Alzheimer's disease & 89 & $66.5 \pm 8.6$ & $44(49): 45(51)$ & $15.4 \pm 8.2^{\ddagger}$ & $4.6 \pm 3.4^{\ddagger}$ \\
\hline Parkinson's disease & 32 & $57.5 \pm 14.1$ & $17(54): 15(46)$ & $1.5 \pm 2.0$ & $1.8 \pm 1.1$ \\
\hline Multiple sclerosis & 41 & $44.6 \pm 13.5^{\ddagger}$ & $18(44): 23(56)$ & ND & $1.0 \pm 0.9$ \\
\hline Control & 18 & $61.8 \pm 13.3$ & $12(67): 6(33)$ & $0.1 \pm 0.3$ & $1.2 \pm 0.7$ \\
\hline
\end{tabular}

ND, not done. *Mean \pm SD; ${ }^{*}$ statistically significant differences $(P<0.0001)$ relative to all other groups by Student's $t$ test or ANOVA. 


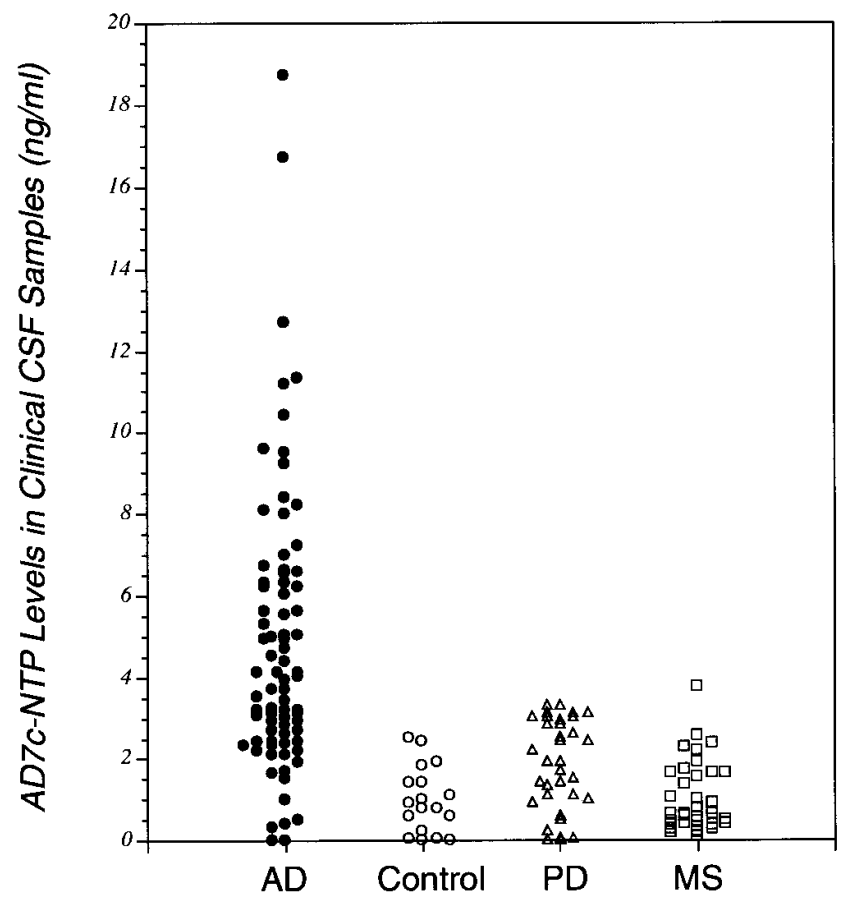

Figure 6. Distribution of AD7c-NTP concentrations ( $\mathrm{ng} / \mathrm{ml})$ in clinical CSF samples from patients with possible or probable $\operatorname{AD}(n=89)$, multiple sclerosis $(M S ; n=41)$, Parkinson's disease $(P D ; n=32)$, or no neurological disease (normal aged controls; $n=18$ ). Approximately $62 \%$ of the patients with possible or probable AD (subsequently confirmed to have definite AD by detailed clinical follow-up and postmortem examination of the brains) had concentrations of AD7c-NTP protein in CSF $>3 \mathrm{ng} / \mathrm{ml}$, compared with $0 \%$ in the control, $2 \%$ in the MS, and $16 \%$ in the PD groups. Similarly, levels of AD7c-NTP above $2 \mathrm{ng} / \mathrm{ml}$ were observed in $89 \%$ of AD and only $11 \%$ of aged controls $(P<0.0001)$.

Analysis of AD7c-NTP levels in postmortem CSF from AD and aged control patients. Postmortem CSF was obtained from 121 patients with histopathologically confirmed end-stage AD. In addition, samples were obtained from 19 neurologically normal aged controls. The control group had a mean age ( \pm SD) $72.5 \pm 6.8$ yr (range: $60-85), 9$ (47\%) males and 10 $(53 \%)$ females, and a mean postmortem interval of $5 \pm 4 \mathrm{~h}$. The AD group had a mean age of 77.3 $\pm 6.5 \mathrm{yr}$ (range: 61-85), 42 (35\%) males and $79(65 \%)$ females, and a mean postmortem interval of $6 \pm 2 \mathrm{~h}$. In the control group, the CSF concentrations (ng/ml) of AD7c-NTP ranged from 0.1 to 3.5 , the mean level $( \pm \mathrm{SD})$ was $1.60 \pm 0.87$, and the $95 \%$ CIL were 1.17-2.03. (Fig. 5; Table I). In the AD group, the CSF concentrations of AD7cNTP ranged from 0.3 to $60.9 \mathrm{ng} / \mathrm{ml}$, the mean level was $9.24 \pm 8.20$, nearly sixfold higher than control $(\mathrm{T}=9.87,138 \mathrm{df}$; $P<0.0001$ ), and the $95 \%$ CIL were 7.7-10.7. Levels of AD7cNTP above $3 \mathrm{ng} / \mathrm{ml}$ were detected in $84 \%$ of the AD samples, compared with $5 \%$ of control $\left(\chi^{2}=52.6, P<0.0001\right)$. Therefore, elevated levels $(>3 \mathrm{ng} / \mathrm{ml})$ of AD7c-NTP in CSF were correlated with the histopathological diagnosis of $\mathrm{AD}(r=$ $\left.0.61 ; r^{2}=0.38 ; \mathrm{T}=9.13 ; P<0.0001\right)$. In contrast, there were no correlations between AD7c-NTP CSF levels and age $(>50$ years), gender, duration of dementia, or postmortem interval.

Population profile of patients included in the clinical study. AD7c-NTP levels were measured in 180 clinical CSF samples from 89 patients with early (possible or probable)
AD, 32 with established PD, 41 with MS or other inflammatory CNS disease, and 18 neurologically intact aged controls (Table I). The mean and corresponding 95\% confidence interval limits for age overlapped among the AD (66.5 $\pm 8.6 ; 95 \%$

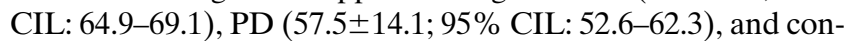
trol (61.8 \pm 13.3 ; 95\% CIL: 56.2-67.4) groups, but the MS patients were significantly younger $44.6 \pm 13.5$; 95\% CIL: $40.3-$ 48.8) than the other three groups $(\mathrm{F}-$ ratio $=38.4 ; P<0.0001)$. Although the gender ratios varied, there were no significant differences among the groups $\left(\chi^{2}=4.55 ; 3 \mathrm{df} ; P=0.21\right)$. BDSS data obtained within 6 mo of the CSF harvests were available for $89 \mathrm{AD}, 11$ control, and $22 \mathrm{PD}$ patients. As expected, the mean BDSS was significantly higher in the AD group (15.4 \pm 8.2 ; 95\% CIL: $13.3-17.5)$ relative to the PD (1.5 \pm 2.0 ; 95\% CIL: $0.3-2.7)$ and aged control (0.1 0.3 ; 95\% CIL: $0.1-$ $0.3)$ groups $(\mathrm{F}$-ratio $=25.95,3 \mathrm{df} ; P<0.0001)$.

Elevated CSF levels of AD7c-NTP in patients with early (possible or probable) $A D$. The mean level of AD7c-NTP was significantly higher in the AD group (4.6 \pm 3.4 ; $95 \%$ CIL: 3.9-5.3) compared with the PD (1.8 \pm 1.1 ; 95\% CIL: 1.4-2.1), MS (1.0 $\pm 0.9 ; 95 \%$ CIL: $0.7-1.3)$, and aged control (1.2 \pm 0.7 ; 95\% CIL: 0.8-1.6) groups (F-ratio $=26.17, P<0.0001)$. Although the distribution of CSF AD7c-NTP levels in the AD group was broad (range: $0-18.7 \mathrm{ng} / \mathrm{ml}$ ), the mean level was two- to fourfold higher than in the other three groups, and $62 \%$ of the samples had AD7c-NTP concentrations above $3 \mathrm{ng} /$ $\mathrm{ml}$ (Table I; Fig. 6), and 89\% were above $2 \mathrm{ng} / \mathrm{ml}$. In contrast, the CSF AD7c-NTP concentrations measured in both the neurological disease and normal control groups were tightly clustered such that levels greater than $3 \mathrm{ng} / \mathrm{ml}$ were detected in only $2.4 \%(n=1)$ of the MS, and $0 \%$ of the aged control samples. In the PD group, $16 \%(n=5)$ of the CSF samples had AD7c-NTP concentrations between 3.1 and 3.3, while the remaining $84 \%$ had levels below $3 \mathrm{ng} / \mathrm{ml}$. Chi-square analysis demonstrated the proportion of AD samples with AD7c-NTP levels above $3 \mathrm{ng} / \mathrm{ml}$ to be significantly greater than in the other three groups $\left(\chi^{2}=51.4 ; 3 \mathrm{df} ; P<0.0001\right)$. Similarly, levels of AD7c-NTP above $2 \mathrm{ng} / \mathrm{ml}$ were observed in $89 \%$ of AD and only $11 \%$ of aged controls $(P<0.0001)$.

Analysis of CSF AD7c-NTP levels in relation to $A D$ dementia and BDSS. All of the patients with early AD were subjected to sequential neurological evaluations and diagnosed with probable $(54 \%)$ or definite (postmortem confirmed: 46\%) AD, 4-10 yr after the initial assessments. The clinical CSF samples used in this study were obtained within 6 mo of the most recent neuropsychiatric and cognitive testing. Linear regression analysis demonstrated significant correlations (Fig. 7) between CSF AD7c-NTP levels and AD diagnosis $\left(r=0.54 ; r^{2}=0.29 ; \mathrm{t}=8.52 ; P<0.0001\right)$ and BDSS $(r=$ $\left.0.66 ; r^{2}=0.44 ; \mathrm{t}=8.1 ; P=0.0001\right)$, but not with age $>49 \mathrm{yr}$ $\left(r=0.06 ; r^{2}=0.004 ; \mathrm{t}=0.87 ; P>0.1\right)$ or gender $(r=0.06$; $\left.r^{2}=0.004 ; \mathrm{t}=-0.82 ; P>0.1\right)$. Stepwise multivariate regression, including BDSS, age $>49 \mathrm{yr}$, and gender in the equation, demonstrated only BDSS to be a significant correlate of CSF AD7c-NTP concentration $\left(r^{2}=0.27 ; \mathrm{t}=4.6 ; P<0.0001\right)$.

Effects of AD7c-NTP overexpression in neuronal cells. Subconfluent cultures of SH-Sy5y cells transfected with pcDNA3 contained round or spindled shape cells with few or no processes (Fig. $8 A$ ). In contrast, $\mathrm{SH}$-Sy5y cells transfected with pcDNA3-AD7c-NTP exhibited extensive neuritic growth with fine interconnecting processes on most cells (Fig. $8 \mathrm{C}$ ). Similar effects were observed in PNET2 human central nervous sys- 

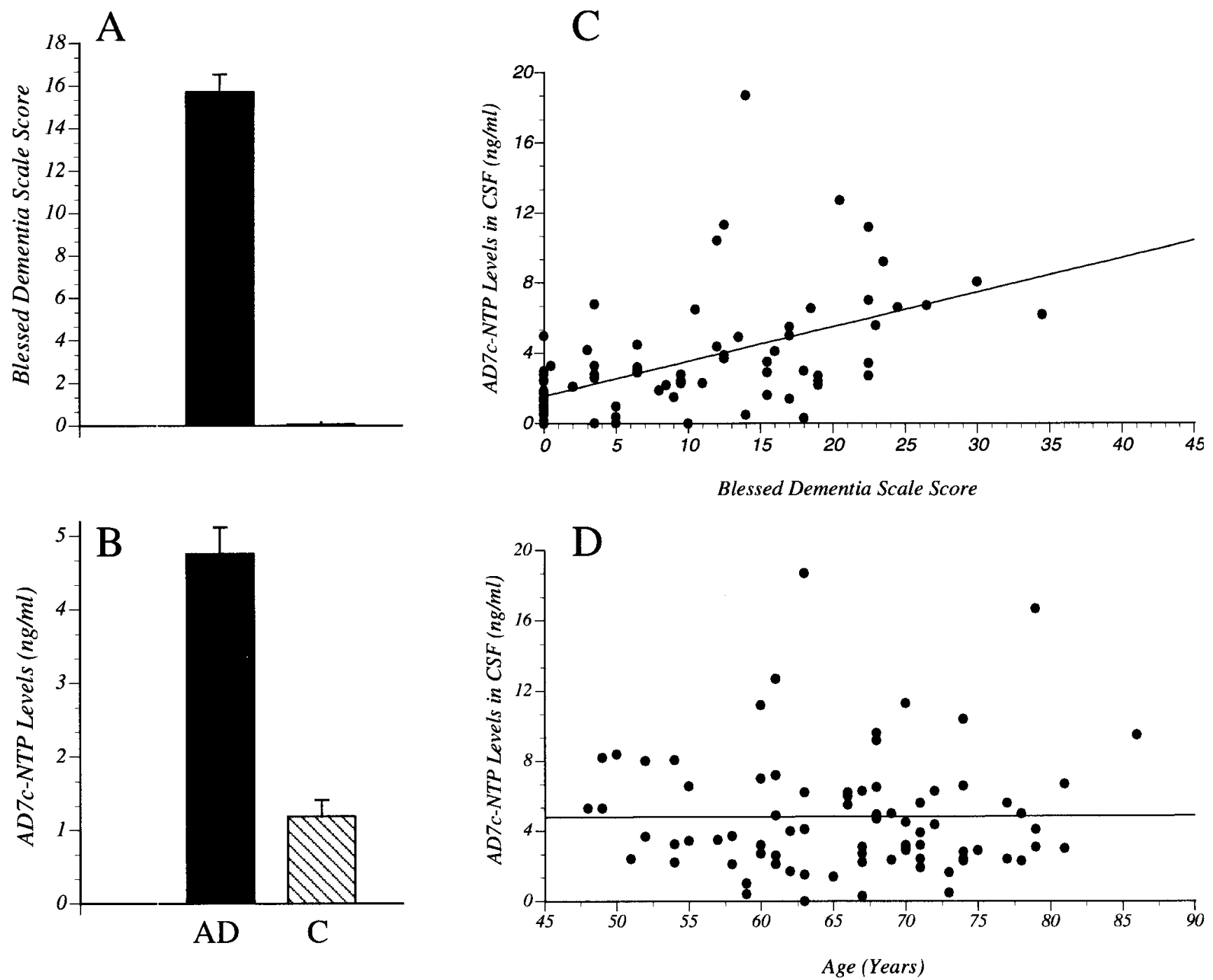

Figure 7. Analysis of AD7c-NTP levels in CSF in relation to BDSS ( $A$ and $C$ ) or patient age $(B$ and $D)$. The AD7c-NTP ELSIA was performed with clinical CSF samples obtained within 6 mo of neuropsychiatric testing. Panels A and B depict the mean $( \pm$ SD) BDSS $(A)$ and corresponding CSF AD7c-NTP levels $(B)$ in patients with possible or probable AD and in cognitively normal aged controls. Linear regression analysis demonstrated a positive correlation between AD7c-NTP concentrations in CSF and BDSS $\left(r^{2}=0.44 ; r=0.66 ; P<0.0001\right)(C)$ but not between AD7c-NTP levels and age between 45 and $90 \mathrm{yr}\left(r^{2}=0.0045\right)$ or gender $\left(r^{2}=0.0038\right)$.

tem-derived neuronal cells (Fig. 8, $B$ and $D$ ). In addition, pcDNA3-AD7c-NTP transfected cultures always contained numerous round, refractile floating cells (dead) which failed to exclude Trypan blue dye. Immunocytochemical staining of stationary cultures using the N3I4 mAb revealed intense labeling of the cell bodies, nuclei and cell processes of SH-Sy5y cells transfected with pcDNA3-AD7c-NTP (Fig. 8, $F$ and $G$ ), and low level or absent immunoreactivity in SH-Sy5y cells transfected with pcDNA3 (empty vector) (Fig. $8 \mathrm{E}$ ). Finally, overexpression of AD7c-NTP in SH-Sy5y neuronal cells stably transfected with pcDNA3-AD7c-NTP resulted in significantly lower densities of viable cells in the cultures, despite normal or slightly elevated levels of DNA synthesis (Fig. $8 H$ ).

\section{Discussion}

The AD7c-NTP cDNA is a novel gene that contains Alu encoded sequences. Alu sequences represent a family of inter- spersed repetitive elements in human and other mammalian genomes (39). Modulation of Alu gene expression during cell proliferation and differentiation suggests a functional role for Alu genes and gene products in these states (40-42). Previous studies demonstrated Alu sequence insertions and rearrangements in mutated genes associated with systemic (43-46) as well as neurological (47) diseases. It will be important to determine whether AD7c-NTP represents a normal or mutated gene. AD7c-NTP gene expression in human brain tissue was verified by six different methods including nucleic acid sequencing of cloned RT-PCR products and detection of the corresponding $\sim 41-\mathrm{kD}$ protein in cerebrospinal fluid. Structure analysis of the deduced amino acid sequence suggests that the AD7c-NTP cDNA encodes a membrane spanning protein. The presence of a TGF $\beta$ motif and IGF-1/insulin hybrid receptor domain suggest that AD7c-NTP expression may be related to cell growth and potentially modulated by IGF-1 or insulin stimulation. This analysis is consistent with the finding that 

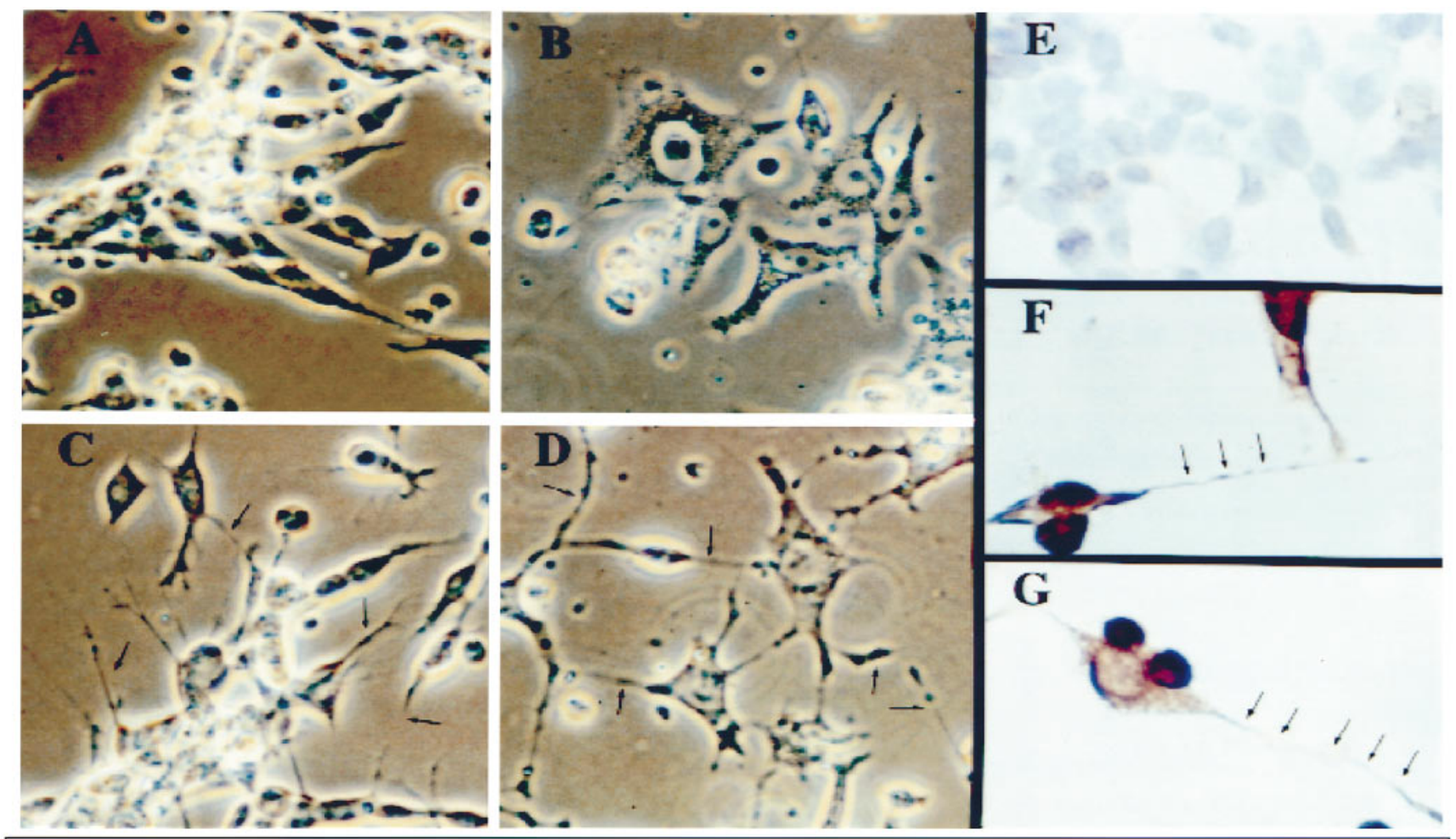

\section{$\mathbf{H}$}

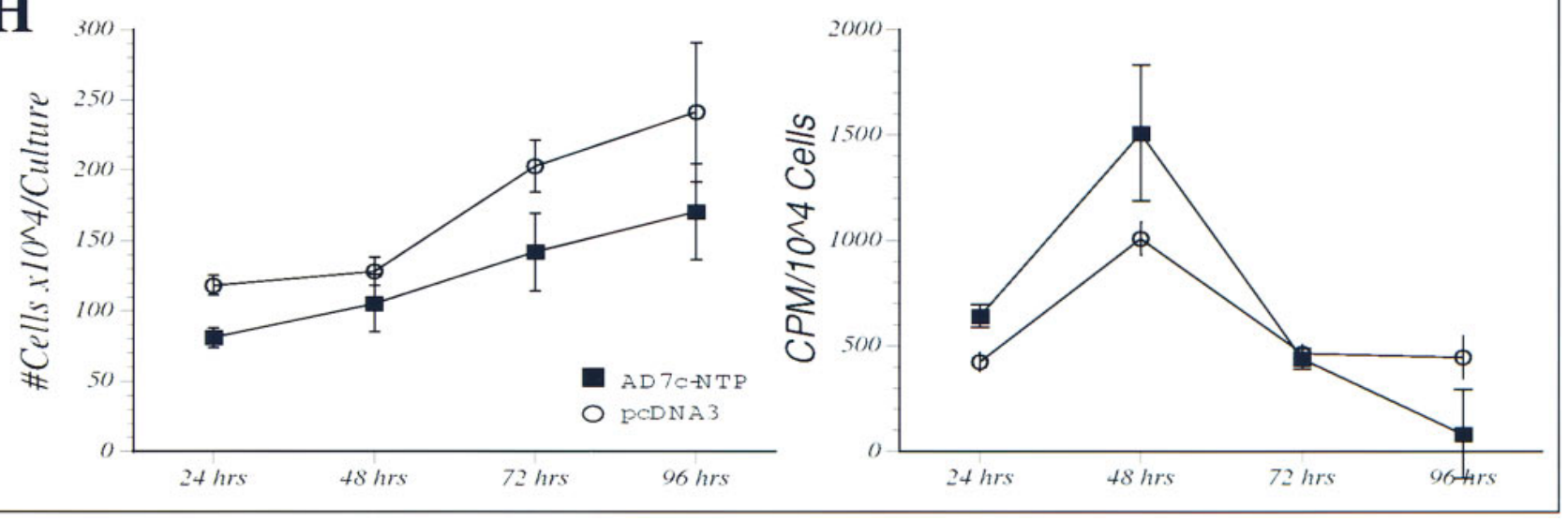

Figure 8. AD7c-NTP overexpression in transfected neuronal cells results in increased neuritic sprouting. $(A)$ SH-Sy5y and $(B)$ PNET2 cells stably transfected with pcDNA3 (empty vector). (C) SH-Sy5y and $(D)$ PNET2 cells stably transfected with pcDNA3-AD7c-NTP. Note fine neuritic processes (arrows) on most cells in $C$ and $D .(E-G)$ Immunocytochemical staining of SH-Sy5y cells stably transfected with pcDNA3 (E) or pcDNA3-AD7c-NTP $(F$ and $G)$ using N3I4 mAb. Note intense labeling of nuclei and cell processes (arrows) in $F$ and $G$ and absent labeling in $E$. Western blot analysis demonstrated expression of the expected $\sim 41-45-\mathrm{kD}$ protein bands (data not shown). Decreased cell viability in pcDNA3-AD7c-NTP transfected SH-Sy5y cells $(H)$. Cell growth and $\left[{ }^{3} \mathrm{H}\right]$ thymidine incorporation into DNA were assessed in synchronized cultures fed with medium containing $10 \%$ FCS. The density of viable cells was determined at each time point $(H$, left panel). Despite higher levels of DNA synthesis $(H$, right panel), cell density was significantly reduced in four replicate AD7c-NTP-transfected cultures compared with control (pcDNA3-transfected) cells.

over-expression of AD7c-NTP causes neuritic growth in stably transfected neuronal cells. Recent preliminary studies also demonstrated increased expression and phosphorylation of endogenous AD7c-NTP-related proteins following insulin stimulation of PNET2 and SH-Sy5y cells (de la Monte, S.M., and J.R. Wands, unpublished observations).

The human tissue studies revealed elevated levels of AD7c-NTP expression in AD relative to aged control brains, and increased AD7c-NTP gene expression localized in AD brain neurons by in situ hybridization and immunohistochemi- cal staining. Although the cDNA was isolated from a library prepared with RNA obtained from a single AD brain, the RTPCR studies confirmed the presence of identical sequences in AD brains. Increased expression of AD7c-NTP occurs in both histologically intact and degenerating neurons and cell processes, and recent studies suggest that abnormal AD7c-NTP protein expression is an early event in AD neurodegeneration (30). Indeed, in vitro studies demonstrated that over-expression of the AD7c-NTP gene in transfected neuronal cells promotes neuritic sprouting and cell death, two principal 
pathological processes in AD neurodegeneration. It will be important to determine in future studies if AD7c-NTP overexpression leads to neuronal degeneration in vivo such as in a transgenic mouse model, and whether the increased AD7c-NTP immunoreactivity observed in AD brains and CSF is primarily the result of aberrantly upregulated gene (mRNA) expression, or accumulation and abnormal processing of the protein.

Recently, we studied the expression of the AD7c-NTP gene by immunohistochemistry and found that the protein accumulated in AD brain neurons (20). AD7c-NTP immunoreactivity colocalizes with tau-immunoreactive neurofibrillary tangles and dystrophic neurites. However, abnormal AD7cNTP gene expression precedes the formation of neurofibrillary tangles, and occurs in neuronal populations that do not yet exhibit neurofibrillary tangle pathology in AD (30). In preliminary studies, we demonstrated that elevated CNS levels of AD7c-NTP were detectable in postmortem ventricular fluid by Western blot analysis (30). In this study, we searched for elevated levels of AD7c-NTP protein in CSF using a recently developed quantitative ELSIA, and sought to determine whether the elevated CSF AD7c-NTP levels were correlated with the severity of dementia in early AD. Simple objective measures to assess $\mathrm{AD}$ neurodegeneration could help in the development of therapeutic agents.

Using the N3I4 and N3C11 antibodies, only a single $\sim 41$ $\mathrm{kD}$ AD7c-NTP-immunoreactive protein was detected in CSF subjected to HPLC fractionation and ELSIA analysis of each fraction (Fig. 4) and significantly elevated levels of AD7c-NTP protein were observed in $\mathrm{AD}$ relative to aged control CSF samples. The $\sim 42-45-\mathrm{kD}$ and $\sim 21-\mathrm{kD}$ AD7c-NTP-immunoreactive bands observed by Western blot analysis of brain tissue were not detected in CSF, perhaps for two reasons: (a) the higher molecular mass species may represent phosphorylated forms of AD7c-NTP which were either not preserved or were never present in the CSF samples; and $(b)$ the N2J1 and N2U6 mAbs which detected the 21-kD AD7c-NTP-related species were not used in the ELSIA or HPLC fractionation studies. Recent studies suggest that the 21-kD AD7c-NTPrelated protein is derived from a distinct $\mathrm{mRNA}$, as we have already isolated and expressed the corresponding cDNA (de la Monte, S.M., and J.R. Wands, unpublished observations).

Levels of 41-kD AD7c-NTP above $3 \mathrm{ng} / \mathrm{ml}$ were detected in $62 \%$ of the early possible or probable AD and $84 \%$ of the definite end-stage postmortem AD CSF samples. Moreover, levels of AD7c-NTP above $2 \mathrm{ng} / \mathrm{ml}$ were observed in $89 \%$ of early clinical AD compared with $11 \%$ of aged control CSF samples. The mean level of AD7c-NTP in CSF from patients with end-stage definite AD was twofold higher than in the early possible or probable AD samples, yet no such difference was observed between the clinical (antemortem) and postmortem aged control CSF levels. This result suggests that AD7cNTP concentrations in CSF may increase with progression of AD neurodegeneration. An important aspect of this study was the availability of archival CSF specimens from patients subjected to systematic prospective assessment of neuropsychiatric and cognitive function and careful follow-up, including postmortem examination of the brains (46\%). In addition, the inclusion of clinical CSF samples from neurological disease controls provides important data concerning the specificity and sensitivity of the AD7c-NTP ELSIA. The lack of correlation between AD7c-NTP levels in CSF and age in both the clinical and postmortem studies suggests that aberrantly in- creased expression of AD7c-NTP reflects neuropathological changes in the brain rather than a nonspecific effect of aging. Moreover, it is unlikely that the reported CNS accumulations of AD7c-NTP protein represent a response to nonspecific injury since similar abnormalities were not observed in patients with multiple sclerosis. Furthermore, the specificity of AD7cNTP as a biochemical marker of AD has been confirmed recently using non-AD dementia control CSF sample (our unpublished observations).

AD7c-NTP levels in CSF were positively correlated with BDSS. Correspondingly, CSF AD7c-NTP levels were not elevated in PD or control patients who had BDSS scores of 0 or 1. In postmortem cases, elevated CSF levels of AD7c-NTP were correlated with end-stage dementia and histopathologically proven AD (high densities of neurofibrillary tangles and senile plaques) rather than age or duration of disease. These findings suggest that increased levels of the $\sim 41-\mathrm{kD}$ AD7c-NTP protein in CSF may mark AD neurodegeneration and correlate with severity of dementia. However, elevated levels of AD7cNTP were not observed in several AD samples. Low levels of AD7c-NTP in CSF could reflect either very early disease (as observed in the antemortem clinical samples), or severe endstage AD with depletion of neuronal populations susceptible to neurodegeneration (as observed in several postmortem cases) (30). Therefore, it would be of interest to examine AD7c-NTP levels in CSF sampled over the course of Alzheimer's disease.

Finally our studies suggest that expression of AD7c-NTP and related genes is modulated with neuritic sprouting, and that overexpression of AD7c-NTP in neuronal cells causes neuritic growth and cell death. Aberrant neuritic sprouting $(15,16,48,49)$ and apoptotic cell death are important features of AD neurodegeneration (50-52). We are led to believe that the overexpression of AD7c-NTP in AD brains and elevated levels in CSF may reflect these neurodegenerative processes, since there is a general correlation of AD7c-NTP levels with the severity of the dementia.

\section{Acknowledgments}

The authors gratefully acknowledge Dr. James Hanley, McGill University, for his advice concerning the statistical analysis of the data.

Supported by National Institutes of Health grants CA-35711, AA-02169, and AA-02666, grants from the American Cancer Society, Nymox Corporation, and from the Tan Yan Lee Foundation.

\section{References}

1. Khachaturian, Z.S. 1985. Diagnosis of Alzheimer's disease. Arch. Neurol. 42:1097-1105.

2. Takman, A. 1993. Epidemiology of Alzheimer's disease. Issues of etiology and validity. Acta. Neurol. Scand. 145(Suppl.):1-70.

3. Corder, E.H., A.M. Saunders, W.J. Strittmatter, D.E. Schmechel, P.C Gaskell, G.W. Small, A.D. Roses, J.L. Haines, and M.A. Pericak-Vance. 1993. Gene dose of apolipoprotein E type 4 allele and the risk of Alzheimer's disease in late onset families. Science. 261:921-925.

4. Lai, F., and R.S. Williams. 1989. A prospective study of Alzheimer disease in Down syndrome. Arch. Neurol. 46:849-853.

5. Tanzi, R.E., G. Vaula, D.M. Romano, M. Mortilla, T.L. Huang, R.G. Tupler, W. Wasco, B.T. Hyman, J.L. Haines, B.J. Jenkins, et al. 1992. Assessment of amyloid beta-protein precursor gene mutations in a large set of familial and sporadic Alzheimer disease cases. Am. J. Hum. Genet. 51:273-282.

6. Levy-Lahad, E., W. Wasco, P. Poorkaj, D.M. Romano, J. Oshima, W.H. Pettingell, C.E. Yu, P.D. Jondro, S.D. Schmidt, K. Wang, et al. 1995. Candidate gene for the chromosome 1 familial Alzheimer's disease locus. Science. 18:973977.

7. Sorbi, S., B. Nacmias, P. Forleo, S. Piacentini, R. Sherrington, E. Rogaev, 
P. St. George-Hyslop, and L. Amaducci. 1995. Missense mutation of S182 gene in Italian families with early onset Alzheimer's disease. Lancet (N. Am. Ed.). 346:439-440.

8. Sherrington, R., E.I. Rogaev, Y. Liang, E.A. Rogaeva, G. Levesque, M. Ikeda, H. Chi, C. Lin, G. Li, K. Holman, et al. 1995. Cloning of a gene bearing missense mutations in early-onset familial Alzheimer's disease. Nature. 375: 754-760.

9. Rogaev, E.I., R. Sherrington, E.A. Rogaeva, G. Levesque, M. Ikeda, Y. Liang, H. Chi, C. Lin, K. Holman, T. Tsuda, et al. 1995. Familial Alzheimer's disease in kindreds with missense mutations in a gene on chromosome 1 related to the Alzheimer's disease type 3 gene. Nature. 376:775-778.

10. Barinaga, M. 1995. Candidate gene for the chromosome 1 familial Alzheimer's disease locus. Science. 269:973-977.

11. Lai, F., and R.S. Williams. 1989. A prospective study of Alzheimer disease in Down syndrome. Arch. Neurol. 46:849-853.

12. LaFerla, F.M., B.T. Tinkle, C.J. Bieberich, C.C. Haudenschild, and G. Jay. 1995. The Alzheimer's A beta peptide induces neurodegeneration and apoptotic cell death in transgenic mice. Nat. Genet. 9:21-30.

13. Lemere, C.A., F. Lopera, K.S. Kosik, C.L. Lendon, J. Ossa, T.C. Saido, H. Yamaguchi, A. Ruiz, A. Martinez, L. Madrigal, et al. 1996. The E280A presenilin 1 Alzheimer mutation produces increased A 342 deposition and severe cerebellar pathology. Nat. Med. 2:1146-1150.

14. Grundke-Iqbal, I., K. Iqbal, Y.C. Tung, M. Quintan, H.M. Wisniewski, and L.I. Binder. 1986. Abnormal phosphorylation of the microtubule-associated protein t (tau) in Alzheimer cytoskeletal pathology. Proc. Natl. Acad. Sci. USA. 83:4913-4917.

15. de la Monte, S.M., S.C. Ng, and D.W. Hsu. 1995. Aberrant GAP-43 gene expression in Alzheimer's disease. Am. J. Pathol. 147:934-946.

16. de la Monte, S.M., and K.D. Bloch. 1997. Aberrant expression of the constitutive endothelial nitric oxide synthase gene in Alzheimer Disease. Mol. Chem. Neuropathol. 30:139-159.

17. Peress, N.S., and E. Perillo. 1995. Differential expression of TGF-beta 1, 2 and 3 isotypes in Alzheimer's disease: a comparative immunohistochemical study with cerebral infarction, aged human and mouse control brains. J. Neuropathol. Exp. Neurol. 54:802-811.

18. Aschner, M. 1996. The functional significance of brain metallothioneins. FASEB (Fed. Am. Soc. Exp. Biol.) J. 10:1129-1136.

19. Goodison, K.L., I.M. Parhad, C.L. White, A.A. Sima, and A.W. Clark. 1993. Neuronal and glial gene expression in neocortex of Down's syndrome. $J$. Neuropathol. Exp. Neurol. 52:192-198.

20. Pasternack, J.M., C.R. Abraham, B.J. Van Dyke, H. Potter, and S.G. Younkin. 1989. Astrocytes in Alzheimer's disease gray matter express alpha 1-antichymotrypsin mRNA. Am. J. Pathol. 135:827-834.

21. May, P.C., M. Lampert-Etchells, S.A. Johnson, J. Poirier, J.N. Masters, and C.E. Finch. 1990. Dynamics of gene expression for a hippocampal glycoprotein elevated in Alzheimer's disease and in response to experimental lesions in rat. Neuron. 5:831-839.

22. Cataldo, A.M., J.L. Barnett, S.A. Berman, J. Li, S. Quarless, S. Bursztajn, C. Lippa, and R.A. Nixon. 1995. Gene expression and cellular content of cathepsin D in Alzheimer's disease brain: evidence for early up-regulation of the endosomal-lysosomal system. Neuron. 14:671-680.

23. Somerville, M.J, M.E. Percy, C. Bergeron, L.K. Yoong, E.A. Grima, and D.R. McLachlan. 1991. Localization and quantitation of $68 \mathrm{kDa}$ neurofilament and superoxide dismutase-1 mRNA in Alzheimer brains. Mol. Brain. Res. 9:1-8.

24. Chandrasekaran, K., T. Giordano, D.R. Brady, J. Stoll, L.J. Martin, and S.I. Rapoport. 1994. Impairment in mitochondrial cytochrome oxidase gene expression in Alzheimer disease. Mol. Brain. Res. 24:336-340.

25. Fischer, B., H. Schmoll, P. Riederer, J. Bauer, D. Platt, and D. PopaWagner. 1995. Complement C1q and C3 mRNA expression in the frontal cortex of Alzheimer's patients. J. Mol. Med. 73:465-471.

26. Yamagishi, M., S. Takami, and T.V. Getchell. 1996. Ontogenetic expression of spot 35 protein (calbindin-D28k) in human olfactory receptor neurons and its decrease in Alzheimer's disease patients. Ann. Otol. Rhinol. Laryngol. 105:132-139.

27. O'Barr, S., J. Schultz, and J. Rogers. 1996. Expression of the protooncogene bcl-2 in Alzheimer's disease brain. Neurobiol. Aging. 17:131-136.

28. de la Monte, S.M., M. Ozturk, and J.R. Wands. 1990. Enhanced expression of an exocrine pancreatic protein in Alzheimer's disease and the developing human brain. J. Clin. Invest. 86:1004-1013.

29. Ausubel, F.M., R. Brent, R.E. Kingston, D.D. Moore, J.G. Seidman, J.A. Smith, and K. Struhl, editors. 1997. Current Protocols in Molecular Biology. John Wiley \& Sons, New York.
30. de la Monte, S.M., R.I. Carlson, N.V. Brown, and J.R. Wands. 1996. Profiles of neuronal thread protein expression in Alzheimer's disease. J. Neuropath. Exp. Neurol. 55:1038-1050.

31. Mirra, S.S., A. Heyman, D. McKeel, S.M. Sumi, B.J. Crain, L.M. Brownlee, F.S. Vogel, J.P. Hughes, G. van Belle, L. Berg, et al. 1991. The consortium to establish a registry for Alzheimer's disease (CERAD). II. Standardization of the neuropathological assessment of Alzheimer's disease. Neurology. 41:479-486.

32. Lee, R.T., K.D. Bloch, J.M. Pfeffer, M.A. Pfeffer, E.J. Neer, and C.E. Seidman. 1988. Atrial natriuretic factor gene expression in ventricles of rats with spontaneous biventricular hypertrophy. J. Clin. Invest. 81:431-434.

33. Dallman, M.J., and A.C.G. Porter. 1991. Semi-quantitative PCR for the analysis of gene expression. In PCR A Practical Approach. M.J. McPherson, P. Quirke, and G.F. Taylor, editors. IRL Press at Oxford University Press, Oxford. 215-224.

34. McKhann, G., D.A. Drachman, M. Folstein, R. Katzman, D. Price, and E.M. Stadlan. 1984. Clinical diagnosis of Alzheimer's disease: report of the NINCDS-ADRDA work group under the auspices of Department of Health and Human Services Task Force on Alzheimer's disease. Neurology. 34:939-944.

35. Bellet, D.H., M. Ozturk, J.M. Bidart, C.J. Bohouon, and J.R. Wands. 1988. Sensitive and specific assay for human chorionic gonadotropin based on anti-peptide and anti-glycoprotein monoclonal antibodies: construction and clinical implications. J. Clin. Endocrinol. Metab. 63:1319-1327.

36. Ozturk, M., D. Bellet, L. Manil, G. Hennen, R. Frydmann, and J.R. Wands. 1987. Physiologic studies of hCG, $\alpha \mathrm{hCG}$, and $\mathrm{\beta hCH}$ as measured by specific monoclonal immunoradiometric assays. Endocrinology. 120:549-558.

37. Biedler, J.L., L. Helson, and B.A. Sprengler. 1973. Morphology and growth, tumorigenicity, and cytogenetics of human neuroblastoma cells in continuous culture. Cancer Res. 33:2643-2652.

38. The, I., A.E. Murthy, G.E. Hannigan, L.B. Jacoby, A.G. Menon, J.F. Gusella, and A. Bernards. 1993. Neurofibromatosis type 1 gene mutations in neuroblastoma. Nat. Genet. 3:2643-2642.

39. Singer, M.F. 1982. Highly repeated sequences in mammalian genomes. Int. Rev. Cytol. 76:67-112.

40. Sakamoto K., C.M. Fordis, C.D. Corsico, T.H. Howard, and B.H. Howard. 1991. Modulation of HeLa Cell growth by transfected 7SL RNA and Alu gene sequences. J. Biol. Chem. 266:3031-3038.

41. White, R.J., D. Stott, and P.W.J. Rigby. 1989. Regulation of RNA polymerase III transcription in response to F9 embryonal carcinoma stem cell differentiation. Cell. 59:1081-1092.

42. Howard, B.H., and K. Sakamoto. 1990. Alu interspersed repeats: selfish DNA or a functional gene family? New Biol. 2:759-770.

43. Li, L., and P.F. Bray. 1993. Homologous recombination among three intragene Alu sequences causes an inversion-deletion resulting in the hereditary bleeding disorder Glanzmann thrombasthenia. Am. J. Hum. Genet. 53:140-149.

44. Kornreich, R., D.F. Bishop, and R.J. Desnick. 1990. Alpha-galactosidase A gene rearrangements causing Fabry disease. J. Biol. Chem. 265:93199326.

45. Shimada, F., M. Tairs, Y. Suzuki, N. Hashimoto, O. Nozaki, M. Taira, M. Tatibana, Y. Ebins, M. Tawata, T. Onaya, H. Makino, and S. Yoshida. 1990 Insulin-resistant diabetes associated with partial deletion of insulin-receptor gene. Lancet (N. Am. Ed.). 335:1179-1181.

46. Lehrman, M.A., D.W. Russell, J.I. Goldstein, and M.S. Brown. 1987. Alu-Alu recombination deletes splice acceptor sites and produces secreted low density lipoprotein receptor in a subject with familial hypercholesterolemia. $J$. Biol. Chem. 262:3354-3361.

47. Wallace, M.R., L.B. Andersen, A.M. Saulino, P.E. Gregory, T.W. Glover, and F.S. Collins. 1991. A de novo Alu insertion results in neurofibromatosis type 1. Nature. 353:864-866.

48. De Kosky, S., and S.W. Scheff. 1990. Synapse loss in frontal cortex biopsies in Alzheimer's disease: correlation with cognitive severity. Ann. Neurol. 27: 457-464.

49. McKee, A.C., K.S. Kosik, and N.W. Kowall. 1991. Neuritic pathology and dementia in Alzheimer's disease. Ann. Neurol. 30:156-165.

50. Su, J.H., A.J. Anderson, B.J. Cummings, and C.W. Cotman. 1994. Immunohistochemical evidence for apoptosis in Alzheimer's disease. Neuroreport. 5:2529-2533.

51. Smale, G., N.R. Nichols, D.R. Brady, C.E. Finch, and W.E. Horton, Jr. 1995. Evidence for apoptotic cell death in Alzheimer's disease. Exp Neurol. 133:225-230.

52. de la Monte, S.M., Y-K. Sohn, and J.R. Wands. 1997. p53 and Fas (CD95)-mediated apoptosis in Alzheimer's disease. J. Neurol. Sci. In press. 